\title{
BENTHIC INVERTEBRATES OF BENCHMARK STREAMS IN AGRICULTURAL AREAS OF EASTERN WISCONSIN-WESTERN LAKE MICHIGAN DRAINAGES
}

By S. J. Rheaume, Bernard N. Lenz, and Barbara C. Scudder

U.S. GEOLOGICAL SURVEY

Water-Resources Investigations Report 96-4038-C

National Water-Quality Assessment Program

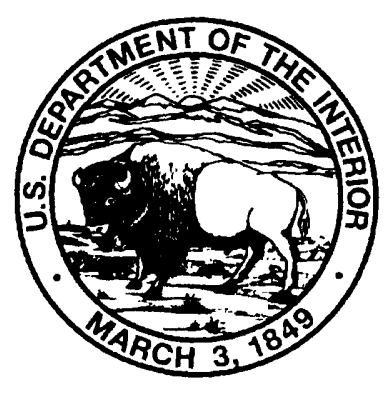

Western Lake Michigan Drainages 


\title{
U.S. DEPARTMENT OF THE INTERIOR BRUCE BABBITT, Secretary
}

\author{
U.S. GEOLOGICAL SURVEY \\ Gordon P. Eaton, Director
}

For additional information write to:

District Chief

U.S. Geological Survey

6417 Normandy Lane

Madison, WI 53719
Copies of this report can be purchased from:

U.S. Geological Survey

Branch of Information Services

Box 25286

Denver, CO 80225-0286 


\section{FOREWORD}

The mission of the U.S. Geological Survey (USGS) is to assess the quantity and quality of the earth resources of the Nation and to provide information that will assist resource managers and policymakers at Federal, State, and local levels in making sound decisions. Assessment of water-quality conditions and trends is an important part of this overall mission.

One of the greatest challenges faced by waterresources scientists is acquiring reliable information that will guide the use and protection of the Nation's water resources. That challenge is being addressed by Federal, State, interstate, and local water-resource agencies and by many academic institutions. These organizations are collecting water-quality data for a host of purposes that include: compliance with permits and water-supply standards; development of remediation plans for specific contamination problems; operational decisions on industrial, wastewater, or watersupply facilities; and research on factors that affect water quality. An additional need for water-quality information is to provide a basis on which regionaland national-level policy decisions can be based. Wise decisions must be based on sound information. As a society we need to know whether certain types of water-quality problems are isolated or ubiquitous, whether there are significant differences in conditions among regions, whether the conditions are changing over time, and why these conditions change from place to place and over time. The information can be used to help determine the efficacy of existing waterquality policies and to help analysts determine the need for and likely consequences of new policies.

To address these needs, the U.S. Congress appropriated funds in 1986 for the USGS to begin a pilot program in seven project areas to develop and refine the National Water-Quality Assessment (NAWQA) Program. In 1991, the USGS began full implementation of the program. The NAWQA Program builds upon an existing base of water-quality studies of the USGS, as well as those of other Federal, State, and local agencies. The objectives of the NAWQA Program are to:

- Describe current water-quality conditions for a large part of the Nation's freshwater streams, rivers, and aquifers.
- Describe how water quality is changing over time.

- Improve understanding of the primary natural and human factors that affect water-quality conditions.

This information will help support the development and evaluation of management, regulatory, and monitoring decisions by other Federal, State, and local agencies to protect, use, and enhance water resources.

The goals of the NAWQA Program are being achieved through ongoing and proposed investigations of 60 of the Nation's most important river basins and aquifer systems, which are referred to as study units. These study units are distributed throughout the Nation and cover a diversity of hydrogeologic settings. More than two-thirds of the Nation's freshwater use occurs within the 60 study units and more than two-thirds of the people served by public water-supply systems live within their boundaries.

National synthesis of data analysis, based on aggregation of comparable information obtained from the study units, is a major component of the program. This effort focuses on selected water-quality topics using nationally consistent information. Comparative studies will explain differences and similarities in observed water-quality conditions among study areas and will identify changes and trends and their causes. The first topics addressed by the national synthesis are pesticides, nutrients, volatile organic compounds, and aquatic biology. Discussions on these and other waterquality topics will be published in periodic summaries of the quality of the Nation's ground and surface water as the information becomes available.

This report is an element of the comprehensive body of information developed as part of the NAWQA Program. The program depends heavily on the advice, cooperation, and information from many Federal, State, interstate, Tribal, and local agencies and the public. The assistance and suggestions of all are greatly appreciated.

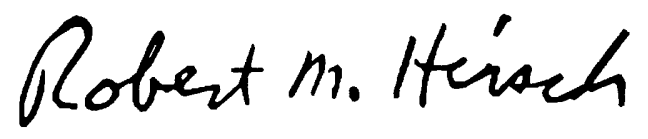

Robert M. Hirsch Chief Hydrologist 



\section{CONTENTS}

Abstract

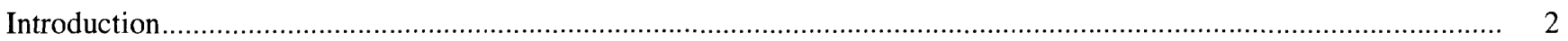

Purpose and scope

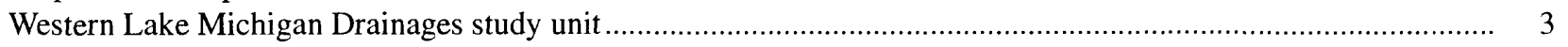

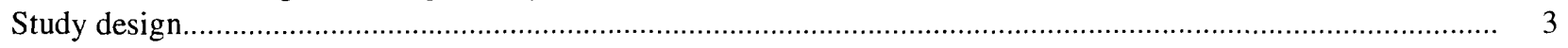

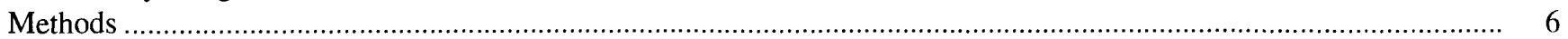

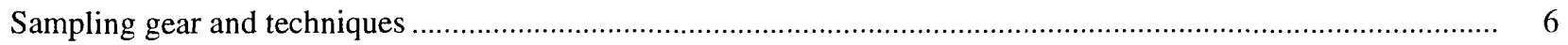

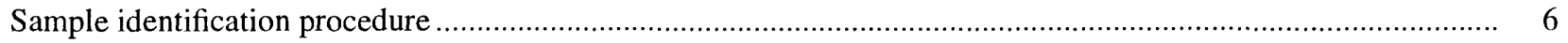

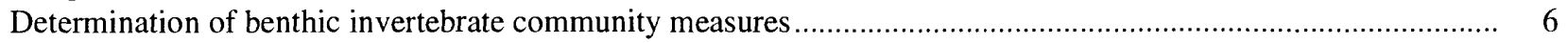

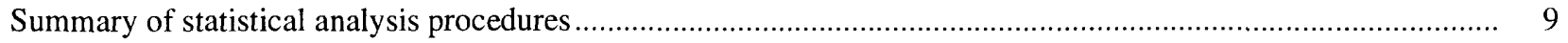

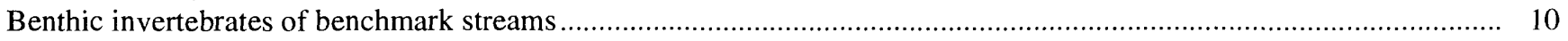

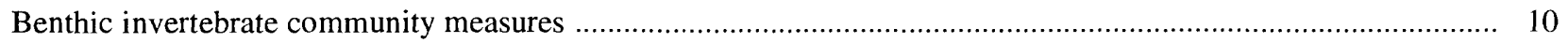

Comparison of benthic invertebrate communities among four relatively homogeneous units .............................. 12

Classification of benthic invertebrate communities ................................................................................ 14

Implications of natural and anthropogenic effects on benthic invertebrates of benchmark streams .............................. 16

Effects of water quality, habitat and environmental setting.................................................................... 16

Suitability of streams as benchmark sites for invertebrate populations ..................................................... 18

Summary .

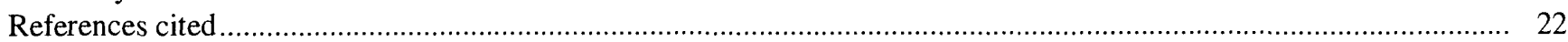

Appendix A: Numbers and types of invertebrates collected in riffle samples from 20 benchmark streams in

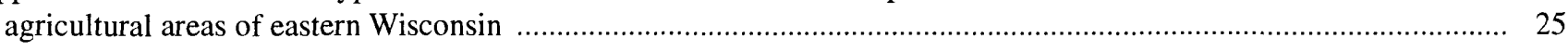

\section{FIGURES}

1. Map showing location of benchmark stream sites and four relatively homogenous units of the Western

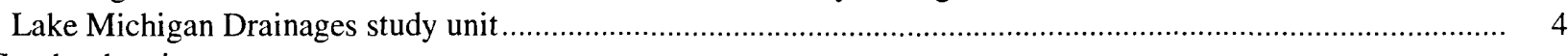

2.-5. Graphs showing:

2. Principal components analysis ordinate axes and groupings of benthic invertebrate community classifications

3. Relation of percentage of agriculture in stream basins to benthic invertebrate community classification groups

4. Scores derived by use of Michigan Department of Natural Resources Great Lakes and Environmental

Assessment Section Procedure 51 (GLEAS), by benthic invertebrate community classification group.........

5. Selected habitat variables related to stream-basin size and benthic invertebrate community classification groups

\section{TABLES}

1. Benchmark streams in agricultural areas of eastern Wisconsin and date of benthic invertebrate collections................. 5

2. Summary statistics of benthic invertebrate community measures...................................................................

3. Benthic invertebrate water-quality ratings determined by other studies at or near benchmark streams sites ............... 12

4. Significant Spearman rank correlation coefficients of benthic invertebrate community measures ............................. 13 


\section{CONVERSION FACTORS AND ABBREVIATED WATER-QUALITY UNITS}

\begin{tabular}{rll}
\hline Multiply & By & To Obtain \\
\hline inch (in.) & 2.54 & centimeter \\
foot (ft) & 0.3048 & meter \\
square mile $\left(\mathrm{mi}^{2}\right)$ & 2.590 & square kilometer \\
acre & 0.4047 & hectare \\
\hline
\end{tabular}

Abbreviated water-quality units: Chemical concentrations and water temperature are given in metric units. Chemical concentration is given in milligrams per liter $(\mathrm{mg} / \mathrm{L})$ or micrograms per liter $(\mu \mathrm{g} / \mathrm{L})$. Milligrams per liter is a unit expressing the concentration of chemical constituents in solution as weight (milligrams) of solute per unit volume (liter) of water. One thousand micrograms per liter is equivalent to one milligram per liter. For concentrations less than 7,000 $\mathrm{mg} / \mathrm{L}$, the numerical values expressed as $\mathrm{mg} / \mathrm{L}$ and $\mu \mathrm{g} / \mathrm{L}$ are the same as for concentrations in parts per million and parts per billion, respectively.

\section{ACKNOWLEDGMENTS}

\section{Technical Support}

Kevin D. Richards, Hydrologic Technician, U.S. Geological Survey, Madison, Wis.

\section{Technical Reviewers}

Charles A. Peters, Supervisory Hydrologist, U.S. Geological Survey, Madison, Wis.

Michael D. Bilger, Biologist, U.S. Geological Survey, Lemoyne, Pa.

Stanley W. Szczytko, Professor, College of Natural Resources, University of Wis., Stevens Point, Wis.

Michael C. Yurewicz, Supervisory Hydrologist, U.S. Geological Survey, Reston, Va.

Stephen K. Sorenson, Supervisory Hydrologist, U.S. Geological Survey, Reston, Va.

\section{Editorial and Graphics}

Betty B. Palcsak, Technical Pub. Editor, U.S. Geological Survey, Columbus, Ohio Michael Eberle, Technical Pub. Editor, U.S. Geological Survey, Columbus, Ohio Michelle M. Greenwood, Cartographer, U.S. Geological Survey, Madison, Wis. Susan Ziegler Jones, Editorial Assistant, U.S. Geological Survey, Madison, Wis. 


\title{
Benthic Invertebrates of Benchmark Streams in Agricultural Areas of Eastern Wisconsin-Western Lake Michigan Drainages
}

\author{
By S.J. Rheaume, Bernard N. Lenz, and Barbara C. Scudder
}

\section{Abstract}

This study describes the benthic invertebrate communities of 20 benchmark streams in agricultural areas of eastern Wisconsin. Streams with minimal adverse effects from human activity were selected from four agricultural areas with differing surficial deposits and bedrock types (relatively homogeneous units, or RHU's). Most aquatic invertebrate orders were well represented in the 20 benchmark stream samples; 217 species and 151 genera within 56 families were identified. Diptera was the best represented order (96 species), followed by Trichoptera (42 species) and Ephemeroptera (26 species). Diptera were the most abundant organisms in terms of numbers of individuals in the sample ( 28 percent of the total) followed by Trichoptera ( 25 percent) and Ephemeroptera (13 percent). Nine species of freshwater mussels were found, but only in 5 of the 20 benchmark streams.

Community measures were calculated for the following: total number of individuals; number of species; number of families; Margalef's diversity index; percent dominant family; percent Ephemeroptera-Plecoptera-Trichoptera (EPT); ratio of EPT to Chironomidae; percent shredders; ratio of scrapers to collectors-gatherers-filterers; Hilsenhoff's Biotic Index; Hilsenhoff's family level biotic index; and mean tolerance value. The SAS statistical software package was used for calculations of variance and correlations, normality checks, and principal components analysis of these measures and to find relations between benthic-invertebrate data and environmental-setting, habitat, and water-quality data.

Coefficients of variation within the RHU's were as great or greater than those for all 20 streams for most measures and RHU's. The specific taxa assemblages present at the sites did not show distinct differences between RHU's or similarities within the RHU's. The covariance and the Kruskal-Wallis tests showed that the benthic invertebrate measures were not related to RHU. These results all indicate that the combined effect of the RHU variables (bedrock geology, texture of surficial deposits, and land use/land cover) were not elemental in describing invertebrate communities in the study-area streams.

A principal components analysis (PCA) was done on the 20 benchmark streams which used the invertebrate population measures as variables. A three-dimensional ordination plot of these components revealed that 18 of the 20 streams could be divided into three groups relative to stream size, available habitat, and water quality. The three classifications of streams include large, warmer streams with slight pollution; deep, mixed-water streams with minimal pollution; and small, cold, pristine headwater streams. The two streams not defined by the three PCA groupings were not suitable to represent benchmark conditions. One site lacked suitable quality habitat or sufficient nutrients to support a healthy population of invertebrates, causing low 
measures of diversity. The other site appeared to be affected by sedimentation and low flows.

The classification groupings did not show any significant relations to percentage agricultural land use. Percentage of agricultural land use varied greatly within each group and the means for each group were similar. All streams in this study had some level of protection from agricultural practices in their basins. Although the intensity of agriculture is known to be a factor causing deterioration of invertebrate populations in past studies, the finding in this study indicated that the level of protection the stream received and other factors such as environmental setting and habitat could be more important to benthic invertebrates than the percentage of agriculture in the basin.

Information gathered from these benchmark streams can be used as a regional reference for comparison with other streams in agricultural areas, based on communities of aquatic biota, habitat, and water quality.

\section{INTRODUCTION}

In 1991, the U.S. Geological Survey (USGS) began implementation of the National Water-Quality Assessment (NAWQA) Program. The objectives of the NAWQA Program are to (1) describe current water-quality conditions for a large part of the Nation's freshwater streams, rivers, and aquifers, (2) describe trends in water quality over time, and (3) improve understanding of the primary natural and human factors that affect water-quality conditions. This information will be useful for planning future management actions and examining their likely consequences. In all, 60 study units are planned to begin activities on a staggered time scale (Leahy and others, 1990). The Western Lake Michigan Drainages study unit was selected as one of the first 20 study units and began data collection and analysis in 1991 .

The effects of agriculture on stream biota is an important issue in the study unit. The introduction of sediments, organic matter, nutrients, and toxic substances such as pesticides into a stream and the effects of channelization and habitat loss may cause deterioration of water quality in agricultural areas (Pajak and others, 1994). Although numerous studies of the aquatic biota and habitat of agriculturally affected streams have been done in the Western Lake Michigan Drainages, very few studies focused on defining the composition of healthy stream communities; that is, those with limited adverse anthropogenic effects. In order for scientists and water-resources managers to measure the effects of changes in agricultural practices on stream communities or the extent of degradation at affected sites, biological communities of healthy streams need to be identified to provide benchmarks against which comparisons can be made. In response to this need, the Western Lake Michigan Drainages study unit team identified 20 minimally affected stream sites to serve as benchmarks for subsequent studies of aquatic communities.

\section{Purpose and Scope}

This report provides information on the benthic invertebrate communities of 20 benchmark streams in agricultural areas of eastern Wisconsin. Environmental characteristics of bedrock geology, texture of surficial deposits, and land use/land cover that are believed to influence water quality in the WMIC study unit were used to subdivided the study unit into 28 relatively homogeneous units (RHU's) (Robertson and Saad, 1996). The 20 benchmark streams sampled are in four of the largest RHU's in the study unit $(1,3,20$, and 26) (Robertson and Saad, 1996). The four RHU's have primarily agricultural land use and differing bedrock and surficial geology. The benchmark streams were sampled for this study from May 1993 through July 1995.

The distribution, relative abundance, and community structure of the benthic invertebrates of these streams are discussed based upon samples collected at specific stream reaches described in the environmental settings report by Rheaume and others (1996). Information is provided for macroinvertebrate communities including richness measures, enumeration, functional feeding groups, and biotic indices of these invertebrate populations. Summaries of sampling gear and techniques, sample-identification procedures, and usefulness of various benthic invertebrate measures are included in this report. Effects of environmental setting, habitat, and water quality on benthic invertebrate communities are discussed. The 20 streams are classified into groups and their suitability as benchmark sites for invertebrate communities are discussed. 
The benthic-invertebrate information included in this report represents only part of the biotic information collected at these streams in the Western Lake Michigan Drainages study unit of the NAWQA Program. Other information collected to define benchmark streams in agricultural areas include environmental settings, habitat, and the algal and fish communities at these sites.

\section{Western Lake Michigan Drainages Study Unit}

The Western Lake Michigan Drainages study unit encompasses a $51,541 \mathrm{~km}^{2}$ area in eastern Wisconsin and the Upper Peninsula of Michigan (fig. 1, inset map). Ten major rivers drain the study unit: the Escanaba and Ford Rivers in Michigan; the Menominee River, which partially defines the state boundary between Wisconsin and Michigan; the Peshtigo and Oconto Rivers in northeastern Wisconsin; the Fox/ Wolf River complex in east-central Wisconsin, which drains into Green Bay; and the Manitowoc, Sheboygan, and Milwaukee Rivers, which drain the southeastern part of the study unit.

The overall population in the study unit is 2,435,000 (U.S. Bureau of Census, 1991). The major cities and their populations are Milwaukee, 628,000; Green Bay, 96,000; Racine, 84,000; Kenosha, 80,000; and Appleton, 66,000. Agriculture is the major land use, with 37 percent of the study unit devoted to cropland and 6 percent to pasture. About 40 percent of the study unit, predominantly the northwestern part, is forested; here streams and lakes offer excellent opportunities for fishing, boating, and other recreation. Lake Winnebago, a 555,442-hectare lake in the Fox River Basin, is a major surface-water feature of the study unit.

\section{Study Design}

The 20 benchmark streams sampled are in four of the largest RHU's in the study unit (1, 3, 20, and 26) (fig. 1). RHU 1 (clayey surficial deposits over carbonate bedrock) and RHU 3 (sandy-till surficial deposits over carbonate bedrock) are in adjacent agricultural areas in the Southeastern Wisconsin Till Plains ecoregion. RHU 20 (sandy surficial deposits over igneous and metamorphic bedrock) and RHU 26 (sandy surficial deposits over sandstone bedrock) are in adjacent areas of agriculture and mixed forests in the North
Central Hardwood Forests ecoregion (Omernik and Gallant, 1988).

Twenty benchmark streams in these four RHU's were selected for sampling (table 1). RHU and landscape classifications, regional ecological patterns, land-cover and land-use information, as well as a detailed description of the 20 benchmark streams and their basins, have been characterized in the environmental setting report by Rheaume and others (1996).

Site selection was based on one or all of the following: (1) available invertebrate, fisheries, and (or) water-quality data that indicated good to excellent water quality; (2) instream habitat restoration for fisheries enhancement; (3) land management to protect riparian vegetation; (4) reconnaissance by USGS personnel; and (5) communication with other professionals doing water-quality work in the area. Many sites were selected because previous studies rated them as having good to excellent water-quality ratings according to a stream arthropod family-level biotic index (William Hilsenhoff, University of Wisconsin-Madison, written commun., 1992; and Stanley Szczytko, University of Wisconsin-Stevens Point, written commun., 1993). This index, developed by Hilsenhoff (1988), summarizes the various tolerances of the benthic arthropod community to organic pollution based on the invertebrates resistance to the effects of increased nutrients concentrations, sedimentation, and lowered dissolved oxygen concentrations associated with organic pollution. Site selections, as well as study design, were also influenced by conversations with Wisconsin Department of Natural Resources (WDNR) personnel and by information provided in habitat improvement and fishery reports (Wisconsin Department of Natural Resources, 1980, 1990; Hunt, 1988; and U.S. Environmental Protection Agency, 1991).

Field data for this report were collected in May and June of 1993 and April, June, and July of 1995 in wadeable-stream reaches. Sampling reach lengths were determined by including repetitive stream-channel geomorphic features of two riffles and two pools or runs, or for a distance of 20 times the stream width if repetitive stream channel features were not available (Meador and others, 1993). Information on the habitat characteristics of the sites can be found in a report by Fitzpatrick and others (1996). Chemical characteristics measured at the sites are listed in table 3 of the environmental settings report by Rheaume and others (1996). 


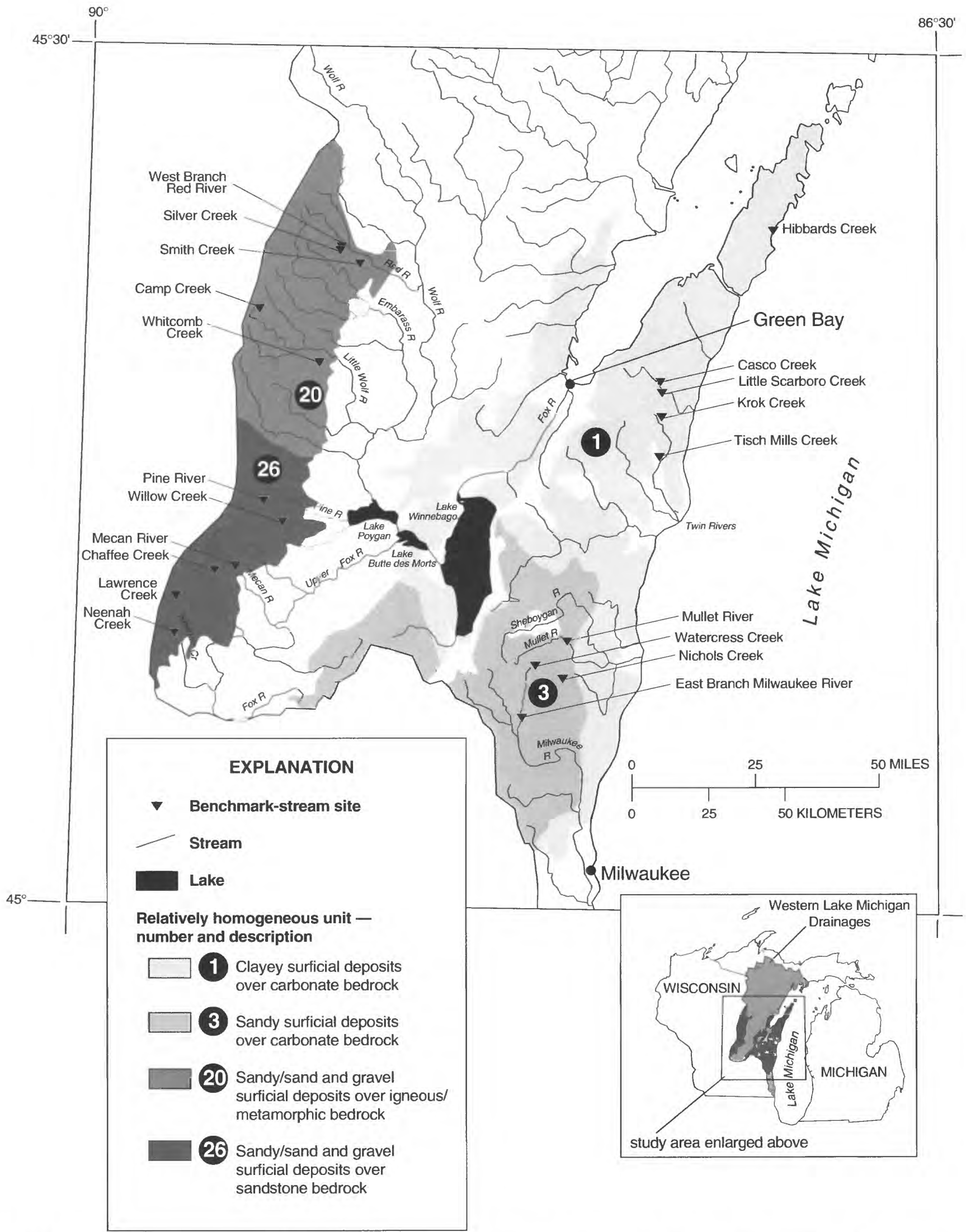

Figure 1. Location of benchmark stream sites and four relatively homogeneous units of the Western Lake Michigan Drainages study unit. 


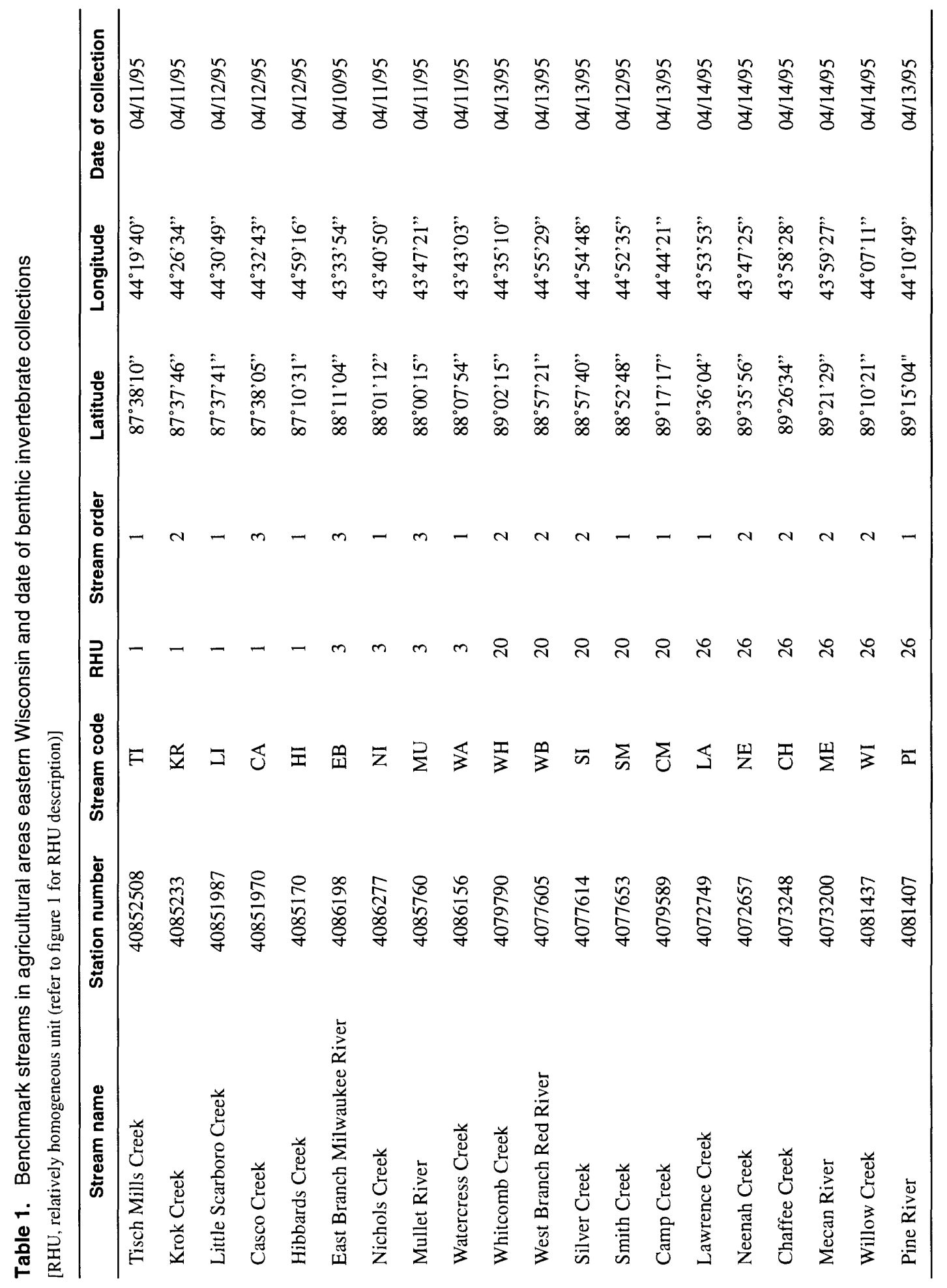




\section{METHODS}

\section{Sampling Gear and Techniques}

Benthic invertebrate sampling consisted of the collection of three replicate samples from the same riffle, usually the largest in each stream reach. A riffle was considered to be the part of the stream where the water flows swiftly over completely or partially submerged obstructions that produce surface agitation. Samples were collected from locations within the riffle where the greatest number and diversity of invertebrates in the reach were most likely to be contained; as inferred by substrate, depth, flow, and canopy cover. Distance between replicate sample locations was rarely greater than $5 \mathrm{~m}$. Samples were collected by use of a modified Slack sampler ( $425 \mu \mathrm{m}$ mesh). The sampling area of each replicate sample was $0.5 \mathrm{~m}$ by $0.5 \mathrm{~m}$ (depth $0.1 \mathrm{~m}$ ) and samples were collected according to the NAWQA protocol for wadeable coarse-grained substrates as described by Cuffney and others (1993a, b).

Field processing of the samples was performed differently than the NAWQA protocol. Each replicate was not a composite of several samples but rather contained only one sample. Samples were elutriated by swirling and were sieved ( $425 \mu \mathrm{m}$ mesh sieve) until sample volumes were less than $750 \mathrm{~mL}$. Samples were preserved in the field in 80 percent ethanol (nondenatured), and within 3 days, they were drained and refilled with 70 percent ethanol and stored until they could be shipped to the laboratory for identification.

Freshwater mussel surveys were done at each of the 20 benchmark streams during August 1995. Personnel from the Wisconsin Department of Natural Resources (WDNR), National Biological Survey ${ }^{1}$ (NBS), and the USGS did viewing-bucket searches of one hour duration at all sites. Presence and absence data from these surveys are at the back of this report (Appendix A).

\section{Sample-Identification Procedure}

Benthic-invertebrate sample processing, enumeration, and taxonomic identifications were done by

\footnotetext{
${ }^{1}$ The name changed to the National Biological Service during this study. The entity is now the Biological Resources Division of the U.S. Geological Survey.
}

the Benthic Macroinvertebrate Laboratory at the University of Wisconsin-Stevens Point, College of Natural Resources. Samples were processed according to techniques described by Hilsenhoff $(1987 ; 1988)$. Each sample was evenly distributed in a sorting tray with 5- by 5 -cm numbered grids (total 15 grids). A grid square was selected using a random number table, and every organism in that grid square was counted. Additional organisms were identified from subsequent, sequentially numbered squares until 125 or more organisms had been identified at the completion of a grid-square identification. Benthic invertebrates were identified to the lowest taxonomic level possible (generally species level) using regional and global keys. The percentage of the total sample volume identified was calculated by dividing the number of grids randomly selected by the total number of grids. Only species identified from the selected grids were used to calculate the benthic community measures. Enumeration measures that require a total number of individuals used a total estimated from the number of taxa identified and the percentage of the total sample volume identified.

\section{Determination of Benthic Invertebrate Community Measures}

Hilsenhoff Biotic Index. The Hilsenhoff Biotic Index (Hilsenhoff, 1982, 1987) was calculated as

$$
H B I=\sum n_{i} t_{i} / N
$$

where

$n_{i}$ is the number of individuals of a genus or species,

$t_{i}$ is the tolerance value of the taxa, and

$N$ is the number of organisms in the sample.

Tolerance values are obtained from Hilsenhoff (1982, 1987). The Hilsenhoff Biotic Index is widely used in the Great Lakes area as a biological assessment of the effects of organic pollution on stream organisms. The index weights the relative abundance of each taxon in terms of its pollution tolerance to determine a community score. Community scores range from 0.0 to 10.0 
and correspond to the following water-quality categories.

\begin{tabular}{cll}
\hline Range & $\begin{array}{l}\text { Water-quality } \\
\text { classification }\end{array}$ & Degree of organic pollution \\
\hline $0.00-3.50$ & excellent & no apparent organic pollution \\
$3.51-4.50$ & very good & possible slight organic pollution \\
$4.26-5.00$ & good & some organic pollution probable \\
$5.01-5.75$ & fair & fairly substantial pollution likely \\
$5.76-6.50$ & fairly poor & substantial pollution likely \\
$6.51-7.25$ & poor & very substantial pollution likely \\
$7.26-10.0$ & very poor & severe organic pollution likely \\
\hline
\end{tabular}

Hilsenhoff (family-level) Biotic Index. Hilsenhoff (family-level) Biotic Index (FBI) uses the same equation as HBI, but in this index, $n_{i}$ is the number of individuals of a family and $t_{i}$ is the tolerance value of that family (Hilsenhoff, 1988). Like the HBI, the FBI is a biological assessment of the effects of organic pollution on stream organisms. This test is generally not as powerful as the generic HBI mentioned above; however, it is a useful comparison because rapid bioassessment community scores for many other streams in Wisconsin and Michigan include only family-level identifications. The water-quality categories of community scores for FBI are similar to those for HBI.

\begin{tabular}{cll}
\hline Range & $\begin{array}{l}\text { Water-quality } \\
\text { classification }\end{array}$ & \multicolumn{1}{c}{ Degree of organic pollution } \\
\hline $0.00-3.75$ & excellent & organic pollution unlikely \\
$3.76-4.25$ & very good & possible slight organic pollution \\
$4.51-5.50$ & good & some organic pollution \\
$5.51-6.50$ & fair & fairly significant organic pollution \\
$6.51-7.50$ & fairly poor & significant organic pollution \\
$7.51-8.50$ & poor & very significant organic pollution \\
$8.51-10.00$ & very poor & severe organic pollution \\
\hline
\end{tabular}

Mean tolerance values. The mean tolerance value (Lillie and Schlesser, 1994) was calculated as

$$
\left(\Sigma t_{i}\right) / N
$$

where

$t_{i}$ is the same tolerance value of the taxa used in the HBI, and
$N$ is the number of organisms in the sample. The calculated tolerance value represents the mean pollution tolerance of the taxa present in a sample and is not weighted. Equal weight is given to each taxon regardless of its numerical abundance; therefore, sparse taxa are just as important as abundant taxa in the final tolerance value. Sparse taxa do not greatly influence the HBI calculation. HBI gives greater significance to abundant taxa. This difference between HBI and mean tolerance value can be important in streams that are characterized by large numbers of relatively few taxa but contain small numbers of many other different taxa of a much different tolerance value than the dominant taxa. (For example, a stream may have a few species of pollution-intolerant taxa that comprise most of the community, and also have many different species of tolerant taxa that are present, but sparse.) The presence of intolerant taxa is vital in characterizing the water quality of the stream (Lillie and Schlesser, 1994), and the mean tolerance value accounts for their presence. The water-quality breakdown of community tolerance value scores is the same as that of HBI and FBI.

Margalef's Diversity Index. Margalef's Diversity Index (MDI) (Margalef, 1969) was calculated for each replicate sample by use of the formula:

$$
M D I=\frac{N \log _{2} N-\sum n_{i} \log _{2} n_{i}}{N}
$$

where

$N$ is the total number of invertebrates in each sample and

$n_{i}$ is the numbers of individuals in each genus. The MDI is based on the theory that a linear relation exists between the number of genera and the number of individuals. A higher MDI indicates a more diverse population. MDI is a popular measure in the Great Lakes area because it is an estimate of community diversity that includes measures of richness and equitability. Generally, more diverse populations indicate better water quality although many very clean streams with limited habitat or flow may not be considered diverse (Rosenberg and Resh, 1993). The MDI for each stream in this study is given as the mean of the three replicates at each site. 
Percent EPT. Samples were identified as described previously, the number of Ephemeroptera, Plecoptera, and Trichoptera (EPT) genera was counted. The percentage of the total number of individuals identified as EPT in each of the three replicate samples was determined and then averaged to determine a percent EPT for the stream. EPT taxa are perceived to be pollution sensitive, indicating better water quality with greater presence (Lenat, 1988).

Ratio of EPT to Chironomidae. The number of Ephemeroptera, Plecoptera, and Trichoptera (EPT) genera and the total number of Chironomidae in the sample were counted. The ratio of total EPT to total Chironomidae was calculated. EPT are perceived to be pollution sensitive and Chironomidae are perceived to be pollution tolerant (Rosenberg and Resh, 1993). An imbalance between these two populations could indicate a stressed environment. A ratio of exactly one indicates a balanced population; a ratio of more than one indicates more EPT and better water quality; and a ratio less than one indicates worse water quality.

Number of species. All three samples from each site were identified as described previously, to the lowest possible taxonomic level such as genus or species. The number of distinct species (or genera if species distinction could not be made) identified in any one or more of the three replicates were counted. Taxa richness generally decreases with decreasing water quality, quality of habitat, and discharge, and stream order; however, some low-order streams do not have high numbers of taxa because of other limiting factors (Weber, 1973; Resh and Grodhaus, 1983).

Number of families. All three replicate samples from each site were identified as described previously and the number of different families counted. Number of families generally decreases with decreasing water quality (Weber, 1973; Resh and Grodhaus, 1983). This test is generally not as powerful as the genus or species level measures mentioned above; however, it is a useful comparison because water-quality bioassessments of many other streams in Wisconsin and Michigan are based on family-level identification.

Percent dominant family. Specimens were identified to the family level as described previously and counted. Counts from the three replicate samples were combined and the dominant families determined.
The percentage of the total number of individuals identified that comprised the dominant family was determined. A community comprised of by relatively few families could indicate community imbalance and signal environmental stress (Plafkin and others, 1989, Bode, 1988).

Estimated number of individuals. The number of individuals contained in each of the three replicate samples was computed by dividing the number of individuals identified in each sample by the percentage of the sample sorted, multiplying by 100 and averaging the three replicates. This community measure can be used as an estimation of the abundance of invertebrates present in the reach. Under certain types of stress, total numbers may either increase or be reduced depending on the types of invertebrates present, their tolerances to the stress, and the interaction of the invertebrates to each other. (Weber, 1973; Resh and Grodhaus, 1983). For example, a stress may cause an overall decline in the invertebrate population or it may affect only certain predator invertebrates. The drop in abundance of predators caused by the stress may allow overall abundance of invertebrates to grow.

Percent shredders. All specimens from the shredder functional group (determined from tables in Merritt and Cummins (1984)) were counted. The percentage of the total number of individuals identified in the sample as shredders was determined. Shredder organisms and their microbial food base are sensitive to toxicants and to modifications of the riparian zone (Plafkin and others, 1989). Decreasing shredder populations can indicate degradation of a stream.

\section{Ratio of scrapers to collectors-gatherers-fil-}

terers. All specimens from the scraper, collector, gatherers, and filterers functional feeding group (determined by use of tables in Merritt and Cummins (1984)) were identified and counted. The ratio of the number of scraper species to the number of collectorgatherers-filterers in the sample was calculated for each replicate, and the mean of the three replicates was determined. These functional groups reflect available food resources. Dominance of collector-gatherers-filterers (ratio less than 1) may reflect increased nutrients in the stream reach (Rosenberg and Resh, 1993). 


\section{Summary of Statistical Analysis Procedures}

Numerous statistical techniques were used to analyze the invertebrate data. This section is an overview of the procedures used. Where possible, references were provided for more specific details of the procedures used. Statistics involving invertebrate measures used the mean value of the measure from all three replicate samples unless otherwise stated in the previous section. All statistical analyses were done using the SAS statistical software package (SAS Institute, Inc., 1990). Information used for the analysis of physical and chemical characteristics of the sites came from a report by Rheaume and others (1996) that describes the environmental settings of these same streams and a report by Fitzpatrick and others (1996) that describes the habitat of these streams. The habitat report classified the quality of the streams using the Michigan Department of Natural Resources GLEAS Procedure 51 (Michigan Department of Natural Resources, 1991); a qualitative method for describing biological and habitat data. The habitat part of the procedure measures and scores, based on benefit to biota in the reach, nine characteristics, or metrics: bottom substrate and available cover, embeddedness, water velocity, flow stability, deposition/sedimentation, pools-riffles-runs-bends, bank stability, bank vegetation, and streamside cover. Scores for each metric were summed and compared to scores from GLEAS reference sites. Total scores represent the quality of habitat at a site with higher quality sites getting a higher value.

Assumptions of univariate normal distribution of the data were assessed using the following techniques: Tukey modified boxplots (Tukey, 1977), stem and leaf plots (Iman and Conover, 1983), normal probability plots (Johnson and Wichern, 1992) and the Wilk-Shapiro test (SAS Institute, 1990). Data distributions for one-half of the data sets were normal or nearly normal; the other half and much of the habitat data (especially categorical data) were not normally distributed, even when log transformed (Fitzpatrick and others, 1996). Because of this, nonparametric statistical methods that do not require the assumption of normal distributions were used in this study. Helsel (1987) describes the advantages of nonparametric statistics for analysis of water-quality data.

The coefficient of variation of the benthic-invertebrate community measures was examined at three levels: (1) among replicate sets; (2) among RHU's; and (3) among all 20 sites. Coefficient of variation among replicates indicates the reliability of the measure (Iman and Conover, 1983). Replicates with little variation and a low coefficient of variation indicate that the measure is stable and that similar values for the measure could be expected if the test was run again. Coefficients of variation calculated for this study were compared to those calculated between replicate samples within a large macroinvertebrate data base used by the WDNR. This data base has standard coefficient of variation values of 15 to 25 percent for reliable measures (Stanley Szczytko, University of Wisconsin-Stevens Point, oral commun., 1996).

Correlation analysis was used to identify invertebrate data with similar distributions among the 20 sites. Rank correlation coefficients, signified by Spearman's rho $(\rho)$, quantify the strength of the monotonic relations between data sets without requiring the relation to be linear (Johnson and Wichern, 1992; Iman and Conover, 1983). The Spearman's rho rank correlations were used in all regression analyses for this study because not all of the data were normally distributed. Significant correlations were defined as those with rho greater than 0.50 or $p$-values less than 0.05 . Data sets that were significantly correlated were plotted against one another to examine the relation graphically.

The Kruskal-Wallis test (Iman and Conover, 1983), a nonparametric analysis of variance (ANOVA) on rank-transformed data, was used to identify significant differences between RHU's; specifically, it was used to indicate whether variance among the sites in an RHU was large enough to mask differences between RHU's. The Tukey studentized range test (Neter and others, 1985) was used to identify which groups from the Kruskal-Wallis test were similar among the RHU's at the 95-percent confidence level.

Principal components analysis (PCA), an objective exploratory technique developed by Pearson (1901) and Hotelling (1933), was used to explain the overall variance in the combination of invertebrate measures through linear combinations of individual measures (Johnson and Wichern, 1992). Plots of principal components axes were used to identify groupings of sites along the axes. The use of PCA does not require a multivariate normal assumption for the data (Johnson and Wichern, 1992). 


\section{BENTHIC INVERTEBRATES OF BENCHMARK STREAMS}

The invertebrates collected at each of the 20 benchmark streams were identified to the lowest taxonomic level possible (Appendix A). These data were used to calculate quantitative aquatic benthic community measures. These measures, along with taxa presence, distribution, and abundance are discussed pertaining to how they were affected by environmental setting, habitat, and water quality.

All major aquatic invertebrate orders were well represented in the 20 benchmark stream samples; 217 species and 151 genera within 56 families were identified. Diptera was the best-represented order (96 species), followed by Trichoptera (42 species) and Ephemeroptera (26 species). Diptera were the most abundant organisms in terms of numbers of individuals in the sample ( 28 percent of the total) followed by Trichoptera (25 percent) and Ephemeroptera (13 percent).

Data on community structure of aquatic arthropods collected from the 20 stream riffle samples are summarized in table 2.

\section{Benthic Invertebrate Community Measures}

Normality tests (stem-and-leaf, box, and normal probability plots) of the invertebrate variables indicated that data sets of percent EPT, number of species, number of families, percent shredders, HBI, and FBI were normally distributed. These same tests indicated that total number of individuals; MDI; percent dominant family; ratio of EPT to Chironomidae; ratio of scrapers to collectors, gatherers, and filterers; and mean tolerance value were not normally distributed.

The most reliable measures for this study (those with the lowest coefficient of variation) tended to be based on the Hilsenhoff water-quality tolerance values (mean tolerance value, FBI, and HBI). Coefficients of variation were 15 percent or less for mean tolerance values, 20 percent or less for FBI; and, except for one value, 20 percent or less for HBI. EPT measures based on species level had many coefficients of variation greater than 25 percent. Coefficients of variation in EPT measures based on generic level exceeded 25 percent for only five sites, thus generic level EPT measures were used in this study. The trophic-function measures were the most unreliable; coefficients of variation between replicates were greater than 25 per- cent for most sites and greater than 50 percent for more than half the sites.

Diversity, enumeration and richness measures varied greatly for streams in this study reflecting the many different invertebrate communities present. Most every combination of diversity, enumeration, and richness was present in the communities found in this study. Streams such as Neenah Creek had many individuals, many taxa, and great diversity while streams such as Watercress Creek and Little Scarboro Creek had fewer individuals, fewer taxa, and marginal diversity. Some streams in the study such as Camp Creek had measures indicating good richness and enumeration measures but had poor diversity measures because they were dominated by one particular taxa. Krok Creek had few individuals but showed high richness and diversity.

Measures related to EPT were the most variable. The presence of EPT taxa in samples ranged from being almost none to comprising over 80 percent of some communities. The ratios of EPT to Chironomidae varied greatly between streams. Percent EPT varied between replicate samples within the same riffle as well as between streams.

Measures based on invertebrates environmental tolerances developed by Hilsenhoff $(1982 ; 1987)$ were least variable. HBI's and FBI's were well correlated with each other in this study and they described the streams similarly. Other studies (Hilsenhoff, 1977, 1982; written communication 1993) calculated HBI and FBI for the same or nearby reaches at 12 of the 20 streams in this study. The water quality ratings given to these reaches during those investigations (table 3 ) are consistent with results obtained in our study.

For certain streams, significantly different relative abundances of tolerant and intolerant species were found based on mean tolerance values and HBI. Mean tolerance values greater than one unit larger than the HBI were determined for Watercress, Nichols, and Chaffee Creeks and Pine River; an indication that the rarer taxa in these streams were more pollution tolerant than the dominant taxa. Mean tolerance values at least four units lower than the HBI were determined for Silver, Casco, and Smith Creeks, an indication that these streams were dominated by a few large populations of pollution tolerant species while also having many species of, but relatively few, pollution intolerant invertebrates (Lillie and Schlesser, 1994).

Relations between the invertebrate measures were examined using Spearman correlations (table 4). 


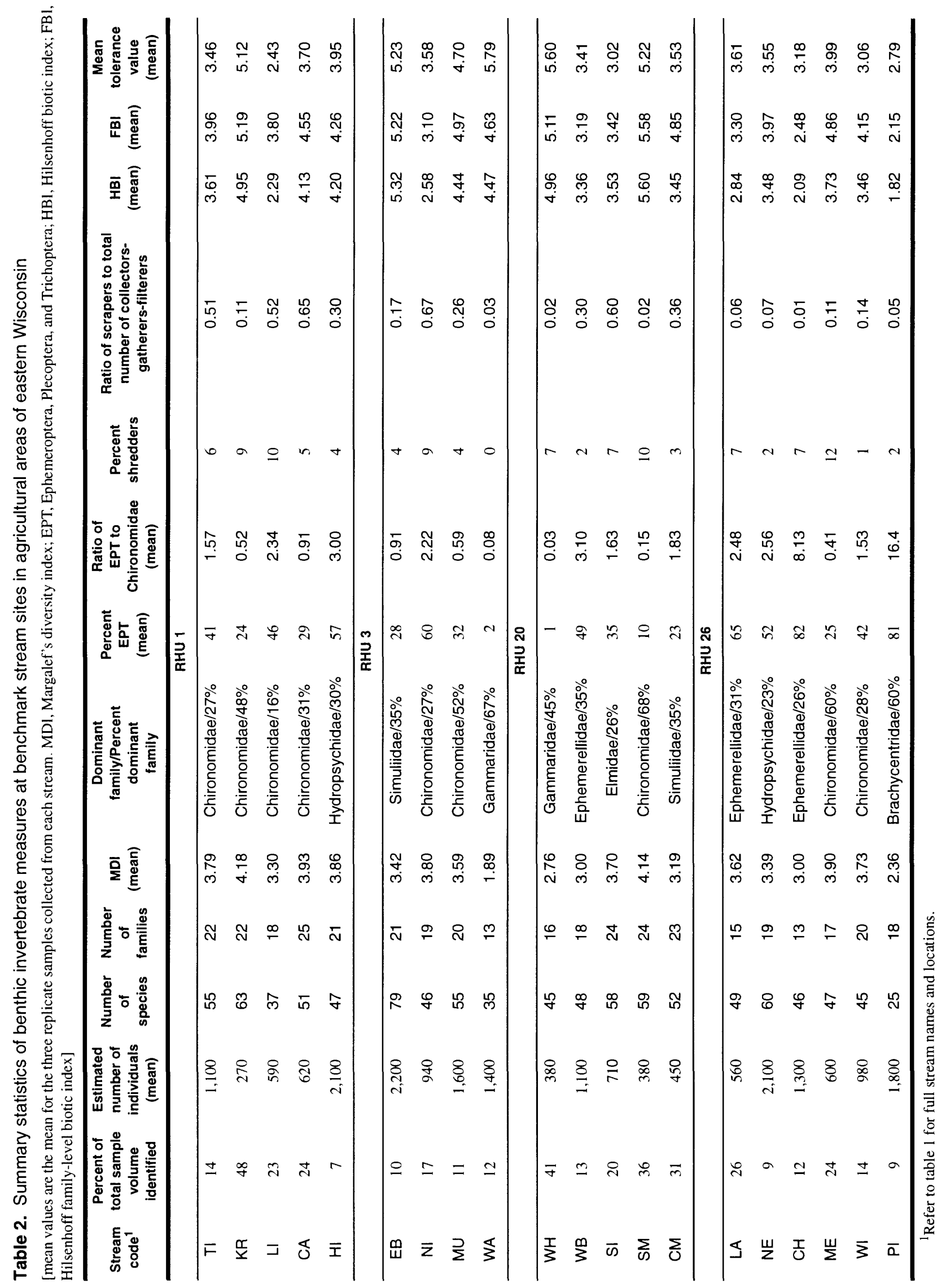


Table 3. Benthic invertebrate water-quality ratings determined by other studies at or near benchmark streams sites from Hilsenhoff $(1977,1982$; written communication, 1993)

\begin{tabular}{|c|c|c|c|}
\hline Stream name & Reach location & Year & Rating \\
\hline Mullet River & same & 1971,1977 , and 1978 & very good \\
\hline Lawrence Creek & less than $1 / 4$ mile downstream & 1972,1977 , and 1978 & excellent \\
\hline Mecan River & $\begin{array}{l}\text { approximately } 6 \text { miles upstream and } 7 \\
\text { miles downstream }\end{array}$ & 1972,1977 , and 1978 & very good to excellen \\
\hline Neenah Creek & approximately 3 miles downstream & 1972,1977 , and 1978 & good \\
\hline Casco Creek & same & 1979 & very good \\
\hline Nichols Creek & same & 1979 & excellent \\
\hline Pine River & same & 1979 & very good \\
\hline Tisch Mills Creek & same & 1979 & excellent \\
\hline Silver Creek & less than 2 miles downstream & 1979 & excellent \\
\hline West Branch of the Red River & approximately 10 miles upstream & 1979 & very good \\
\hline Whitcomb Creek & approximately 7 miles downstream & 1979 & very good \\
\hline Willow Creek & approximately $2-1 / 2$ miles downstream & 1979 & excellent \\
\hline
\end{tabular}

Measures based on environmental tolerance (HBI, FBI, mean tolerance value, and percent EPT) are related based on their correlations $(\rho=0.74$ to 0.90$)$. Shredders were more predominate in small diverse communities as indicated by the relationship of percent shredders to total number of individuals in a population $(\rho=-0.58 ; p=0.0075)$ and $\mathrm{MDI}(\rho=0.55$, $p=0.012)$. The number of families were correlated with the ratio of scrapers to collectors $(\rho=0.53$; $p=0.016$ ), an indication that organic pollution that caused a decline in scraper to collector ratio, also decreased diversity (Pajak and others, 1994). Populations of pollution-tolerant taxa usually were not dominated by one taxon (Washington, 1984). Correlations in this study support this by showing populations strongly dominated by one family had higher tolerance values $(\rho=0.63 ; p=0.0031)$ and lower percent EPT $(\rho=-0.46 ; p=0.039)$.

\section{Comparison of Benthic Invertebrate Communities Among Four Relatively Homogeneous Units}

The covariance and the Kruskal-Wallis test show that the benthic invertebrate measures did not relate strongly to RHU. The covariances for invertebrate community measures at streams in each of the 4 RHU's were less than those for all 20 streams for only two benthic invertebrate community measures: HBI and the ratio of EPT to Chironomidae abundance. Four measures: FBI, MDI, total number of individuals, and percent dominant family had covariances for 3 RHU's less than those for all 20 streams. Kruskal-Wallis tests indicated 16 habitat variables discussed by Fitzpatrick and others (1996) were significantly different among RHU's; however, none of the benthic invertebrate variables were found to be significantly different among RHU's in this study. Additionally, coefficients of variation within each of the 4 RHU's were as great or greater than those for all 20 streams for most measures. These relations indicate that the factors used in the RHU designation (bedrock geology, texture of surficial deposits, and land use/land cover) did not significantly affect the invertebrate populations and were not elemental in describing the species assemblages of benthic invertebrates in these streams.

Other researchers have observed that Omernik's aquatic ecoregions (Omernik and Gallant, 1988), which are based on soils, land-surface form, potential natural vegetation, and land use/land cover, were useful in determining species assemblages of invertebrates (Whittier and others, 1988) and fish (Hughes and others, 1987; Lyons, 1989; Whittier and others, 1988) of "minimally-impacted" or "least-impacted" streams. The only statistically significant difference determined in this study between the ecoregions was 


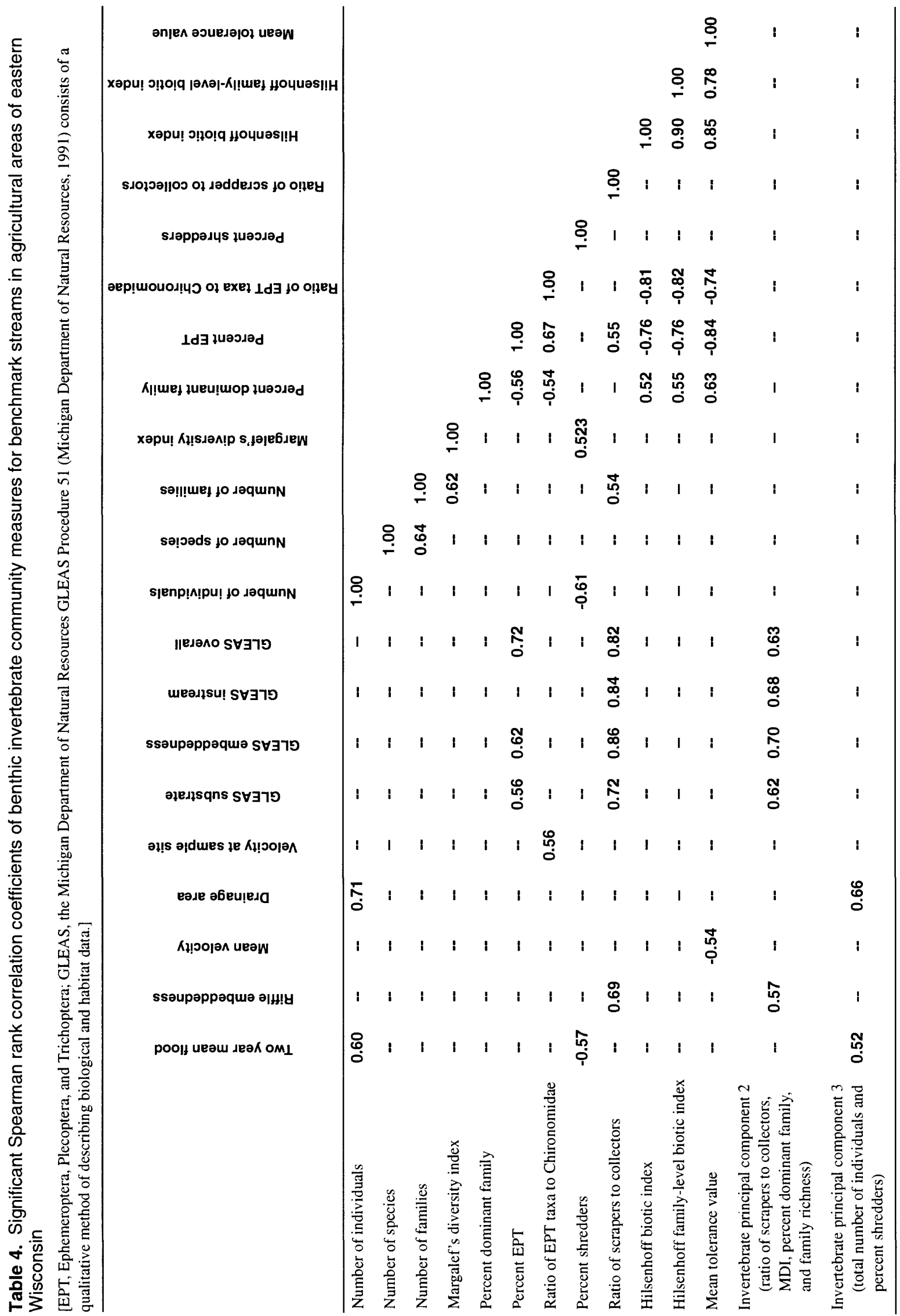


for the ratio of scrapers to collector-gatherer-filterer, a measure which is quite variable.

The low sample number in this study precludes any statistically cogent conclusions as to the existence, or lack thereof, of relations between the RHU's or ecoregions and invertebrate species assemblages in the 20 streams, rather, the study suggests possible relations in the data. Because of this, the RHU classification groupings were still considered even though another classification of the twenty sites was developed using principal component analysis.

Trends in the average mean tolerance values, HBI's, and FBI's by RHU were similar; highest in RHU 3, lowest in RHU 26. The largest difference between mean tolerance values and HBI was in RHU's 3 and 26. Other trends between RHU's were: RHU 1 had highest average MDI (3.8) and ratio of scrapers to collectors, gatherers, and filterers (42); RHU 3 had the highest average number of individuals (1500) and RHU 20 had the lowest (600); and RHU 26 had the lowest average MDI (2.73) and ratio of scrapers to collectors, gatherers, and filterers (7.3). Chironomidae was the dominant family at 9 of the 20 streams; 6 of which were from RHU 1 and 3; RHU's underlain by carbonate bedrock.

The percentage of shredders was low for all streams ( 5 or less at half of the streams) and they were as variable within RHU's as they were between the 20 streams studied. These low percentages usually indicate the presence of toxins or modification of the riparian zone; however, because of the universally low percentages, the functional feeding group classification used in this study is in question. It is possible that the low ratios were due to the classification system and not the actual population. A different functional feeding group classification system may have indicated a greater presence of shredders and thus higher ratios.

\section{Classification of Benthic Invertebrate Communities}

A principal component analysis (PCA) was done on the 20 streams using invertebrate population measures as variables. The first principal component accounted for 38 percent of the variance. It was primarily related to measures that described the tolerance of invertebrates to organic pollution: HBI, FBI, percent EPT, and the ratio of EPT to Chironomidae. The second principal component accounted for 27 percent of the variance and was related to the ratio of scrapers to collectors and diversity measures: MDI, percent dominant family, and family richness. The third principal component accounted for 13 percent of the variance and was primarily related to the measures of total number of individuals and percent shredders. None of the remaining principal components were statistically significant by themselves. A three-dimensional ordination plot of these components revealed that 18 of the 20 streams could be divided into 3 groups (fig. 2). The taxonomic table (appendix A), the invertebrate-population measures calculated from it (table 2), environmental setting and habitat were used to describe these three groups.

Group X consists of six streams: East Branch of the Milwaukee River, Krok Creek, Mecan River, Mullet River, Smith Creek, and Whitcomb Creek. Invertebrate-population measures for these streams indicated fair to good water quality, determined by HBI, FBI, and mean tolerance values which ranged from 3.7 to 5.6. These streams were characterized by populations consisting mostly of Chironomidae (midges), Gammaridae (scuds), Hydropsychidae (net-spinning caddisflies), Simuliidae (black flies), and Ceratopogonidae (no-see-ums). The streams in this group tended to be dominated by midges ( $25-68$ percent), however, large numbers of scuds and black flies were also common. Diversity and richness measures indicated good water quality, however, populations of pollution-tolerant invertebrates were well represented. Less tolerant EPT taxa were missing or present in noticeably low abundance. Most of the streams in group X reach summer water temperatures that are considered high enough to be lethal to some species of trout (Rheaume and others, 1996).

Group Y consists of seven streams: Chaffee Creek, Camp Creek, Hibbards Creek, Lawrence Creek, Neenah Creek, West Branch of the Red River, and Willow Creek. These streams invertebrate-population measures indicated good to excellent water quality, determined by HBI, FBI, and mean tolerance values ranging from 2.1 to 4.8 . These streams were characterized by diverse populations consisting primarily of Ephemerellidae (mayflies), Chironomidae (midges), Elmidae (riffle beetles), Hydropsychidae (net-spinning caddisflies), Brachycentridae (tube-case caddisflies), Simuliidae (black flies), and Baetidae (mayflies). Diversity- and richness-measure ratings were high and populations of less tolerant invertebrates were well represented. Stream populations contained a high percentage of EPT taxa (23-82 percent), 


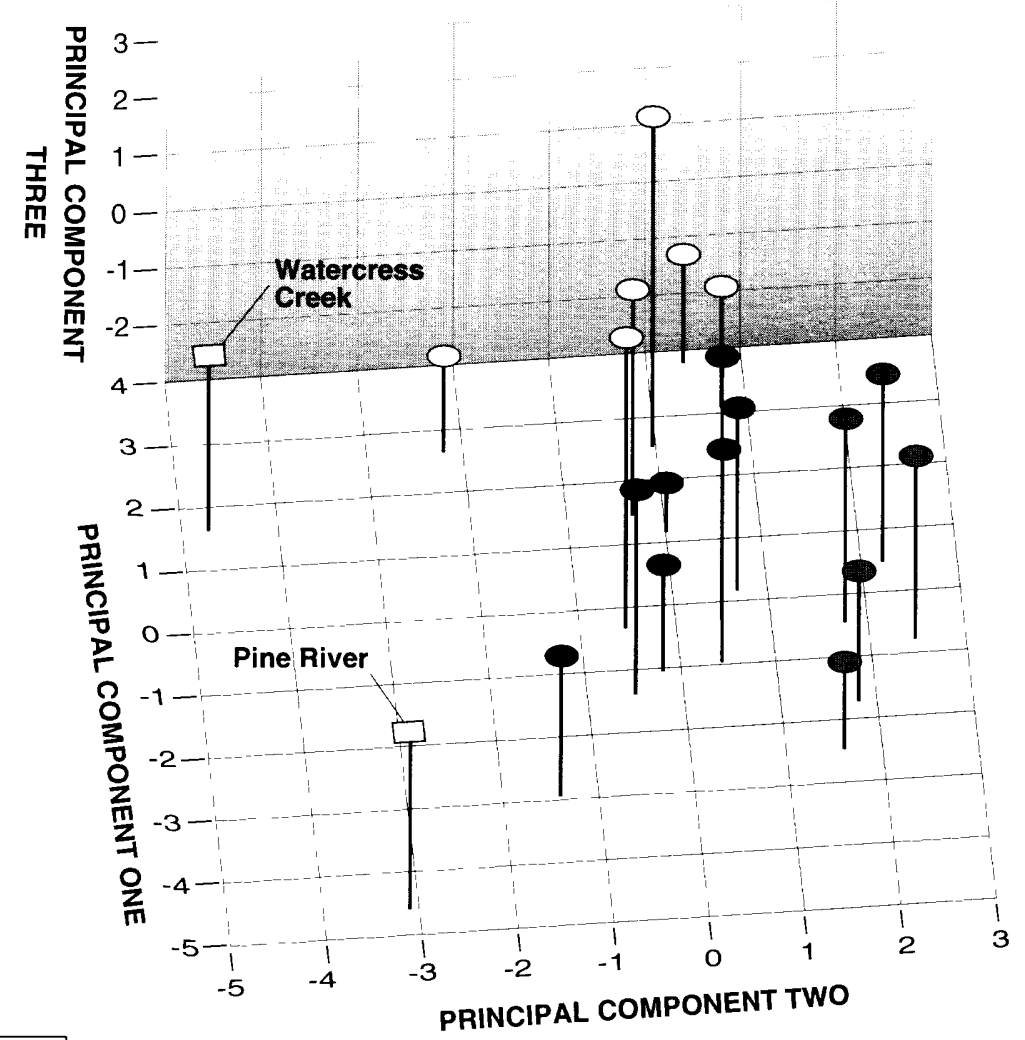

\section{EXPLANATION}

Group X sites

Group Y sites

Group Z sites

Non-grouped sites

Definitions:

PRINCIPAL COMPONENT ONE: tolerance to organic pollution

PRINCIPAL COMPONENT TWO: ratio of scrapers to collectors-gatherers-filterers and diversity

PRINCIPAL COMPONENT THREE: total number of individuals and percentage shredders

Figure 2. Principal components analysis, ordinate axes and groupings of benthic invertebrate community classifications for benthic invertebrate community classifications for benchmark streams in agricultural areas of eastern Wisconsin. 
as well as a high EPT taxa to Chironomidae ratios (1.5 to 8.1 ) indicating the presence of healthy populations of less tolerant mayflies, stoneflies, and caddisflies. All of these streams are considered coldwater streams and were stocked with brook and brown trout; however, high summer water temperatures tend to limit natural reproduction of trout in some of these stream reaches (Rheaume and others, 1996).

Group Z consists of five streams: Casco Creek, Little Scarboro Creek, Nichols Creek, Silver Creek, and Tisch Mills Creek. These streams invertebratepopulation measures HBI, FBI, and mean tolerance value (ranging from 2.3 to 4.5 ) indicated very good to excellent water quality. These streams were characterized by highly diverse populations consisting primarily of less tolerant Chironomidae (midges), Elmidae (riffle beetles), Ephemerellidae (mayflies), Baetidae (mayflies), Tipulidae (crane flies), and Hydropsychidae (net-spinning caddisflies). These streams also contained a good mix of the invertebrates least tolerant to pollution including: Nemouridae (stoneflies), Leptophlebiidae (mayflies), Glossosomatidae (scraper caddisflies), and Brachycentridae (tube-case caddisflies). Diversity was excellent, Chironomidae were usually the dominant family but never composed more than 31 percent of the total sample. High ratios of scrapers (Glossosomatidae) to total number of collectors-gatherers-filterers indicated little or no organic pollution. All of these streams were considered springfed cold water streams that support natural brook trout reproduction (Rheaume and others, 1996). Two of the three streams (Silver and Nichols Creeks) ranked excellent/good, in terms of habitat characteristics, by Fitzpatrick and others (1996) were in this group. The average GLEAS score for group Z (101) was significantly higher than scores for groups $X$ and $Y(82$ and 84) Fitzpatrick and others, 1996).

The Pine River and Watercress Creek were not defined by any of the three PCA groupings. Pine River is a small coldwater stream with FBI, HBI, mean tolerance value, and EPT measures all indicating excellent water quality. The stream had low richness and diversity, which according to Hilsenhoff (1987) is characteristic of many cold, low-order headwater streams with pristine water quality. Sixty percent of the population is Brachycentridae that have a very low tolerance to organic pollution of any type (tolerance values of 0 to 1) (Hilsenhoff, 1987).

The invertebrate population of Watercress Creek is highly dominated by Gammaridae (67 percent) which are fairly tolerant organisms, most likely reflecting the presence of some organic pollution in the stream. This creek is subject to seasonal low flows, which limit many invertebrate populations, and is closely bordered by row crop agriculture that probably results in substantial agricultural runoff to the stream (Rheaume and others, 1996). Watercress Creek has a low total number of taxa (species and families), few shredders and especially low percent EPT taxa (8) and related ratios. $\mathrm{HBI}, \mathrm{FBI}$, and mean tolerance values indicate that some organic pollution is present. This stream is rated the lowest in the habitat evaluations done by Fitzpatrick and others (1996).

\section{IMPLICATIONS OF NATURAL AND ANTHROPOGENIC EFFECTS ON BENTHIC INVERTEBRATES OF BENCHMARK STREAMS}

\section{Effects of Water Quality, Habitat, and Environmental Setting}

The effects of water quality, habitat, and environmental setting on macroinvertebrates can be detected in population abundance and diversity (Washington, 1984). Community measures calculated from taxonomic data are commonly used to define these effects; however, many site-specific factors such as available habitat and flow characteristics also affect these communities, confounding the interpretation of the water quality defined by these measures (Rosenberg and Resh, 1993).

Water-quality samples were collected at the time of invertebrate collection during relatively low flows. Values and constituents collected can be found in the environmental settings report by Rheaume and others (1996). No samples exceeded the WDNR's Water Quality Standards for Wisconsin Surface Waters (WDNR, 1989). The comparison of water-quality and habitat data to the invertebrate measures, done by use of Spearman correlations, indicated that nutrient concentrations appear to affect benthic invertebrate populations. Total nitrogen is the best indicator of the overall nutrient level in the streams. Low total nitrogen concentrations are found in streams with limited degradation from organic pollution and generally support more diverse, abundant populations of pollutionintolerant invertebrates. Intermediate levels of organic pollution may favor certain deposit- or suspensionfeeding macroinvertebrate groups that become abun- 
dant; however, groups less tolerant of the sedimentation and lower dissolved oxygen concentrations commonly associated with organic contamination will start to disappear. High levels of pollution and degradation of water quality can limit a population to only a few very tolerant species (Rosenberg and Resh, 1993). Total nitrogen (Kjeldahl) concentration was inversely related to percent EPT $(\rho=-0.64 ; p=0.0034)$ and had a positive relation with $\mathrm{HBI}, \mathrm{FBI}$, and mean tolerance value ( $\rho=0.66$ to $0.53 ; p=0.0032$ to 0.018 ). Relations between nitrite plus nitrate concentrations and these same measures were similar, but much weaker.

The correlations between nutrient concentrations and number of species $(\rho=0.489 ; p=0.0336)$ showed increased diversity with increased nutrient concentration. Nutrient concentrations were low in the small, first-order streams and the adverse effects of organic pollution were not evident. However, nutrient concentrations may have been so low that the productivity of the streams was affected indicating that nutrient concentration was the limiting factor to productivity and thus diversity in these low-order streams. Nitrite plus nitrate concentrations were low- est in RHU's 26 and 20 (Rheaume and others, 1996). These RHU's also had smaller populations of periphyton and macrophytes which thrive in nutrient rich waters (Fitzpatrick and others, 1996), and these RHU's had the lowest ratio of scrapers to collectors, gatherers, and filterers (7.3) and (26.0) respectively. Scrapers feed on algal populations. Low nutrient levels and ratios of scrapers to collectors, gatherers, and filterers suggest a decrease in the availability of food sources for scrapers. Light limitations caused by canopy cover may also limit the growth of food sources needed by scrappers. Without a food source the number of scrapper present also decreases.

The percentage of the drainage basin that was in agricultural land uses did not have any significant correlations to the invertebrate communities found. The classification grouping also did not show any significant relations to percentage agricultural land use (fig. 3). Percentage of agricultural land use varied greatly within each group and the means for each group were similar. All the streams in this study were protected, to some degree, from agricultural effects by buffer strips and other environmentally minded practices. Although

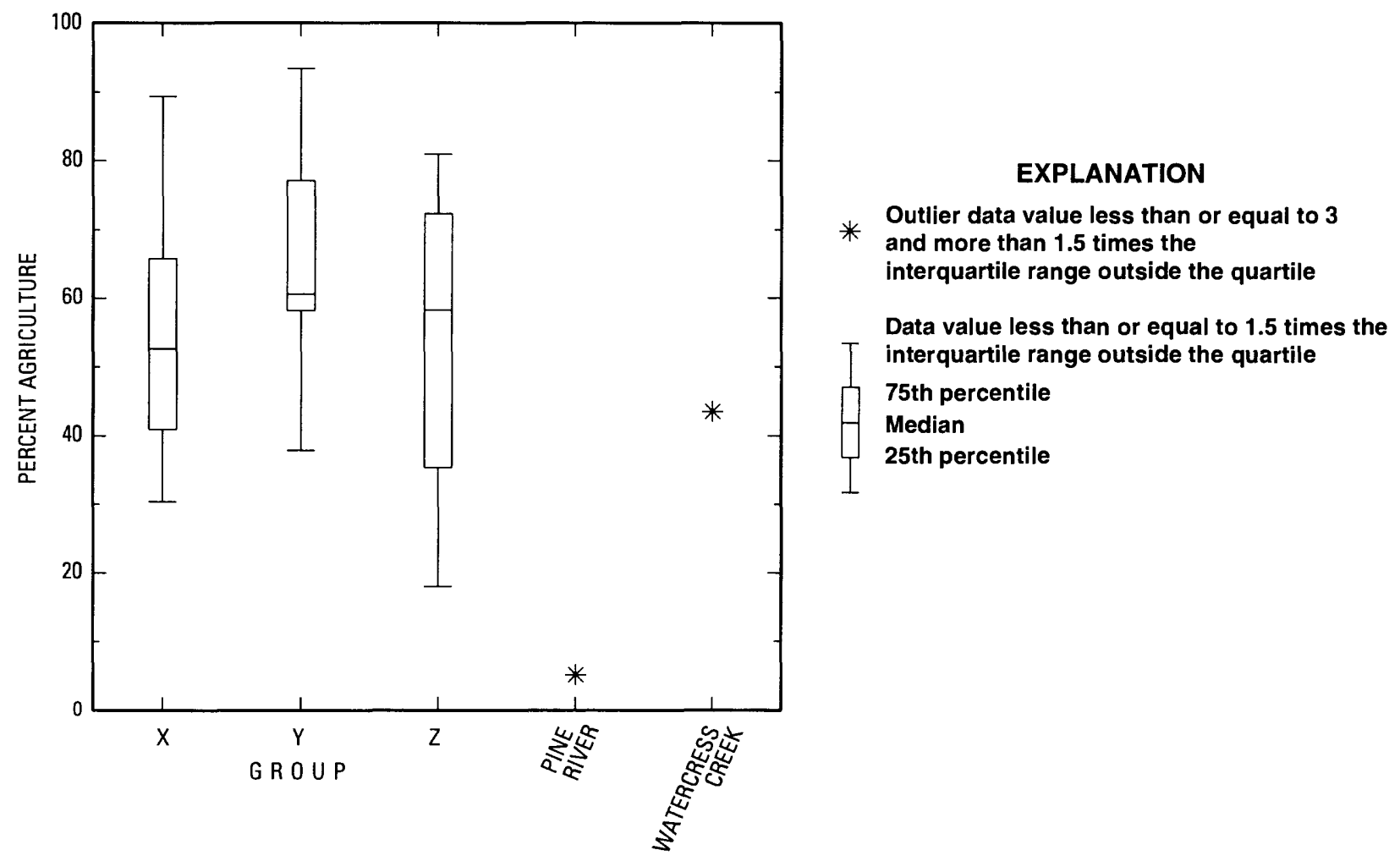

Figure 3. Relation of percentage of agriculture in stream basins to benthic invertebrate community classification groups for benchmark streams in agricultural areas of eastern Wisconsin. 
the intensity of agriculture has been shown to be a factor causing deterioration of invertebrate populations in past studies (Pajak and others, 1994), the findings in this study indicated that the level of protection the stream receives and other factors such as environmental setting and habitat could be more important to benthic invertebrates than the percentage of agriculture in the basin.

A stream with excellent water quality but inadequate habitat may limit invertebrate populations (Washington, 1984). Spearman correlations were used to examine relations between the individual measures and the PCA variables used in the classification section of this report. Several habitat variables concerned with stream basin size had an effect on invertebrate measures. More total number of individuals per sample were present in streams with larger drainage areas $(r=0.63 ; p=0.0032)$, whereas fewer numbers of individuals were present in first-order streams. Drainage area was related to principal component 3 (total number of individuals and percent shredders; $\rho=.62$ ). This indicated larger streams contained more organic matter and could support greater numbers of invertebrates.

Embeddedness in the riffles was related to principal component 2 (ratio of scrapers to collectors and diversity) $(\rho=-0.547)$ and was correlated with the ratio of scrapers to collectors $(\rho=-0.704)$. Highly embedded areas had less exposed rock surfaces on which algae grow. Because scrapers depend on algae as a food source, greater embeddedness resulted in less available food and fewer scrapers.

MDI decreased with percent run $(\rho=-0.46$; $p=0.048)$ and increased with percent riffle $(\rho=0.43$, $p=0.066$ ), an indication that streams with riffles supported a more diverse population of invertebrates than streams containing mostly runs; possibly because riffles offered habitat for invertebrates and aeration in the riffles tended to increase the oxygen level in the streams.

GLEAS scores were compared with invertebrate measures and PCA groupings by use of boxplots (fig. 4) and Spearman rank correlations. The overall GLEAS scores were significantly higher for group Z (fig. 4A). Further, the substrate and instream cover component scores were most different between groups indicating the greater importance of this component, in explaining the invertebrate classifications, over the channel morphology or riparian and bank structure components (fig. 4B-D), which indicated that instream habitat characteristics were most important to invertebrates.

Spearman rank correlations of benthic invertebrate measures to GLEAS scores were considered significant if $\rho>0.7$. Significant correlations included the overall GLEAS score to percent EPT and the ratio of scrapers to collectors, gatherers, and filterers. The ratio of scrapers to collectors, gatherers, and filterers was also related to the combined scores of the substrate and instream cover, bottom substrate scores, and embeddedness scores.

In general, of the three groups, Group X had higher order streams, larger drainage areas with higher width-to-depth ratios, and much greater macrophyte coverage (fig. 5). These larger streams have a larger potential source area of contaminants that negatively affected invertebrates. The values of group $X$ measures indicated that these invertebrate populations may be affected by contamination. Group Y streams were deeper, with low width-to-depth ratios, and low percentages of riffles. Group Z streams tended to be headwater-type streams with smaller drainage areas and the lowest discharges and velocities. In addition, they had low open-canopy angles, greater percent riffles, little woody debris and few scuds. Watercress Creek, which did not plot in one of the three PCA groupings, had the greatest amount of woody debris and was dominated by scuds which thrive on woody debris.

\section{Suitability of Streams as Benchmark Sites for Invertebrate Populations}

Streams in this study suitable as benchmark sites tended to group into three types. These groupings are controlled by a combination of environmental setting, habitat and water quality of the streams. All three healthy invertebrate community groupings appeared to have limited adverse anthropogenic effects and can be used as reference sites against which comparisons can be made. Scientists and water-resources managers can use these benchmarks to identify biological communities of healthy streams, to measure the effects of changes in agricultural practices on stream communities, or to determine the extent of degradation at affected sites. When used as reference sites, the benchmark sites and the individual streams to which they are compared, must have similar environmental setting and habitat. Two of the streams in the study did not fall into any of the three groupings and may not be suitable as benchmark sites. 

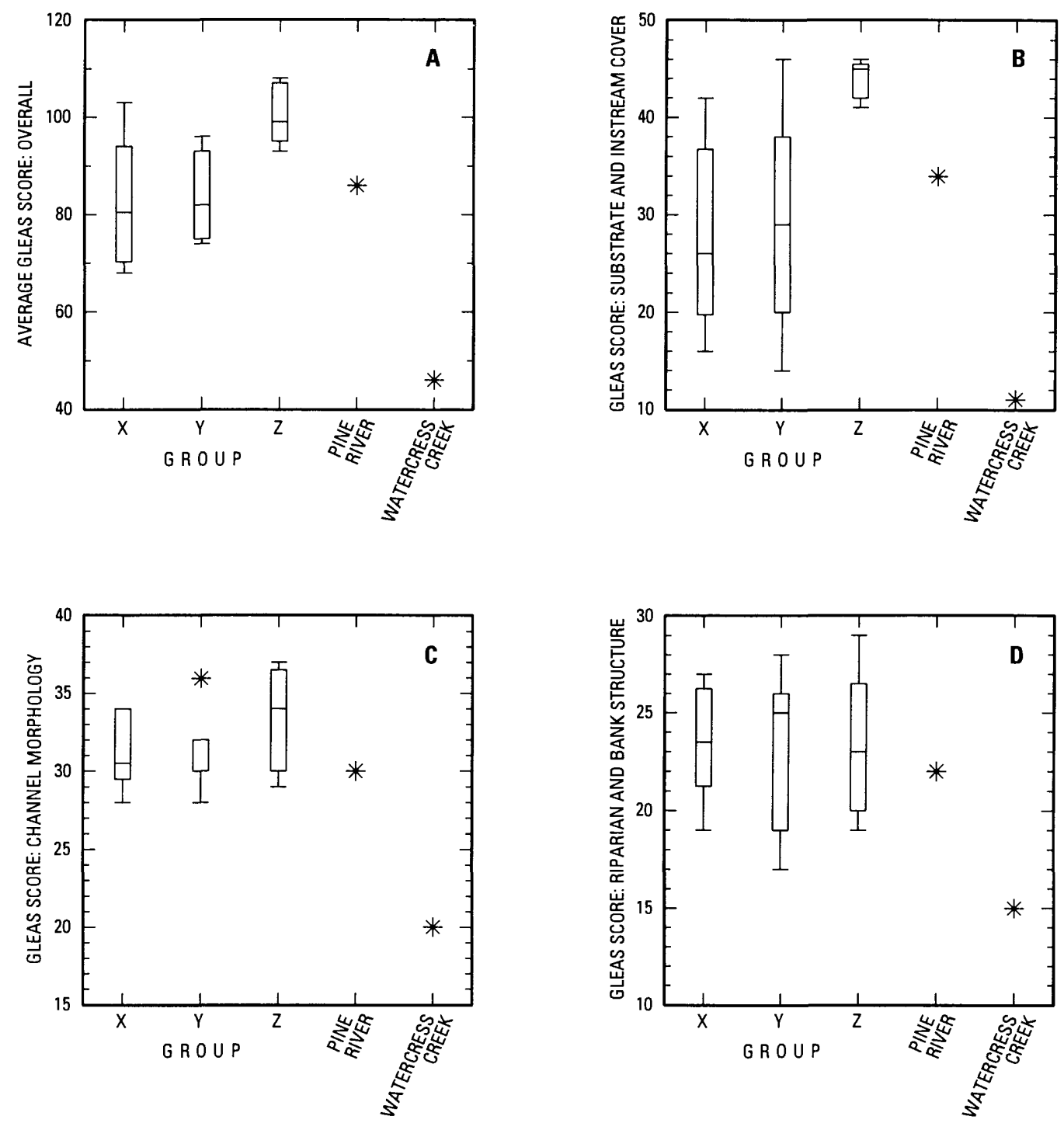

\section{EXPLANATION}

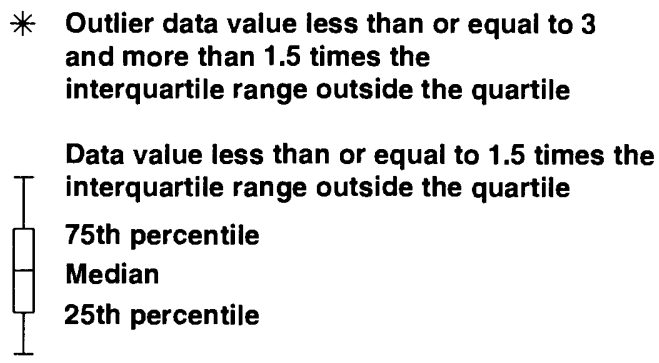

Figure 4. Scores derived by use of Michigan Department of Natural Resources Great Lakes and Environmental Assessment Section Procedure 51 (GLEAS), by benthic invertebrate community classification groups, for benchmark streams in agricultural areas of eastern Wisconsin. 

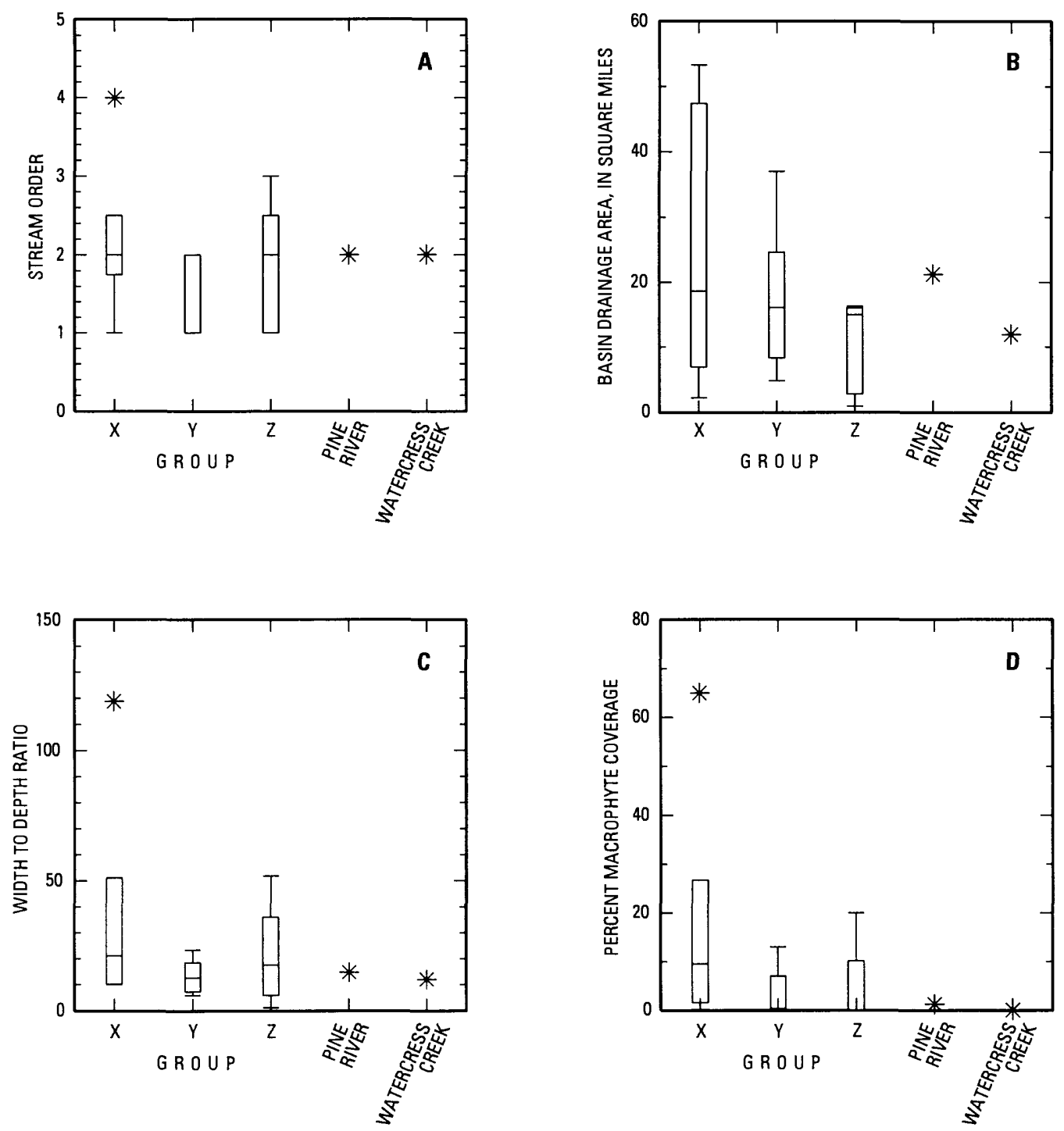

\section{EXPLANATION}

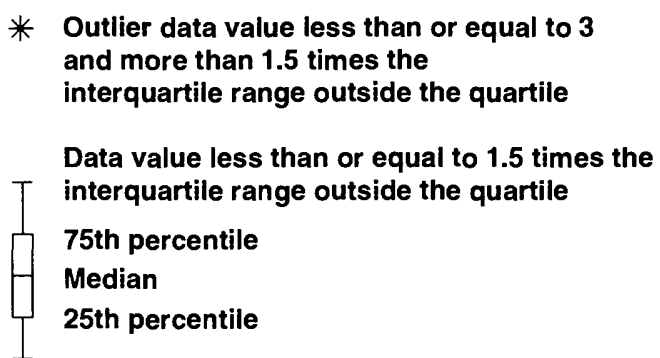

Figure 5. Selected habitat variables related to stream-basin size and benthic invertebrate community classification groups for benchmark streams in agricultural areas of eastern Wisconsin. (Groups are described in the section "Classification of Benthic Invertebrate Communities.") 
Group X streams are large, warmer streams without observed springs. They tend to rank lower than other steams in the study using benthic invertebrate measures of water-quality, but are still ranked either fair or good. They support primarily pollutiontolerant species and prolific macrophytes which indicate that some organic pollution may be affecting these streams, however, it is slight compared to amounts typically found in other agricultural areas (Pajak and others, 1994). These streams can still be used as benchmark sites for similar types of streams in the area.

Group Y consists of deeper streams with few riffles. These streams receive limited spring flow, and tend to warm in the summer. Benthic invertebrate populations in these streams are diverse with both tolerant and intolerant species present. Community measures rank water quality as good to excellent. Invertebrate populations show little or no effect of organic pollution. Group Y streams make very good benchmark streams for many of the agricultural streams in the study area that have similar habitat and environmental settings.

Group Z consists of small, cold, ground-water fed, headwater streams with more riffles and less open canopy than other streams in the study. These streams have GLEAS scores which are considerably higher than the other streams in the study, an indication of higher quality habitat. Invertebrate populations are very diverse and include many intolerant and tolerant species. The benthic invertebrate measures indicate very good to excellent water quality and minimal or no organic pollution. These streams are good benchmark sites for small headwater streams.

Pine River was very similar to streams in group $\mathrm{Z}$ and would rank as one of the better streams in that group except that it has low diversity. This lack of diversity may be caused by a low nutrient concentration, indicated by water quality samples, or by poor quality habitat, indicated by the GLEAS score; both of which limit productivity in the stream. Although this stream has limited impacts of anthropogenic effects, caution should be applied if it is used as a benchmark site. The Pine River should be only compared to similar first order streams with limited productivity caused by poor quality habitat and low nutrient concentrations.

Watercress Creek has lower rankings for all of the invertebrate measures. It also ranked lowest in the habitat evaluations (Fitzpatrick and others, 1996). This stream had large amounts of sediments and woody debris containing many scuds and is subjected to periods of very low flow. This stream has a poor waterquality ranking and is not suitable as a benchmark site for invertebrate populations, but could be useful for future studies on the causes of stream degradation.

\section{Summary}

The effect of agriculture on stream biota is an important issue in the Western Lake Michigan study area. The introduction of sediment, organic matter, nutrients and toxic substances into a stream and the effects of channelization and habitat loss may cause degradation of water quality in agricultural areas (Pajak and others, 1994). Although numerous studies of the aquatic biota and habitat of agriculturally affected streams have been done in the basin, very few studies have focused on defining the composition of a healthy stream community with limited adverse anthropogenic effects.

The benthic invertebrate communities of 20 benchmark streams were described in this report. The 20 streams were selected because anthropogenic activities were thought to have had little effect on the health of the stream community. The 20 sites were located in four relatively homogeneous units (RHU's) (Robertson and Saad, 1996) in agricultural areas with differing bedrock and surficial geology. Three replicate benthic invertebrate kick samples were collected from each stream and preserved. Sample processing, enumeration, and taxonomic identifications were done by the Benthic Macroinvertebrate Laboratory at the University of Wisconsin-Stevens Point, College of Natural Resources.

All major aquatic invertebrate orders were well represented in the 20 benchmark stream samples; 217 species and 151 genera within 56 families were identified. Diptera was the best-represented order (96 species), followed by Trichoptera (42 species) and Ephemeroptera (26 species). Diptera were the most abundant organisms in terms of numbers of individuals in the sample ( 28 percent of the total), followed by Trichoptera (25 percent), and Ephemeroptera (13 percent).

The following community measures were calculated: total number of individuals; number of species; number of families; Margalef's diversity index; percent dominant family; percent EPT; ratio of EPT to Chironomidae; percent shredders; ratio of scrapers to 
collectors-gatherers-filterers; Hilsenhoff's biotic index; Hilsenhoff's family level biotic index; and mean tolerance value. The SAS statistical software package was used to run normalcy, variance, correlation, and principal components analysis on these measures and to find relations between benthicinvertebrate data and environmental-setting, habitat, and water-quality data.

One-half of the measures were normally distributed. The lowest coefficients of variation were from measures based on Hilsenhoff water-quality tolerance. Covariance and Kruskal-Wallis tests showed that the RHU designation was not significant in grouping the invertebrate communities. A principal components analysis (PCA) was done on the 20 streams; invertebrate-population measures were used as variables. The first three principal components accounted for 78 percent of the variance. These were most heavily related to measures that describe the tolerance of invertebrates to organic pollution ( 38 percent); ratio of scraper to collectors, gatherers, and filterers and measures of diversity ( 27 percent); and total number of individuals and percent shredders (13 percent). A three dimensional ordination plot of these components revealed that 18 of the 20 streams could be divided into three groups. These groupings, along with habitat, environmental setting, and water-quality data, were used to classify these benchmark streams.

Classifications of benchmark streams by use of benthic-invertebrate measures divided stream types by size, available habitat, and water quality. The three types of streams include larger, warmer streams with slight pollution; deeper, mixed-water streams with minimal pollution; and small, cold, pristine headwater streams. Of the two streams not suitable for use as benchmark sites, one lacked suitable quality habitat or was limited by low nutrient concentrations, causing low measures of diversity. The other stream appeared to be affected by sedimentation and low flows.

The classification groupings did not show any significant relations to percentage agricultural land use. Percentage of agricultural land use varied greatly within each group and the means for each group were similar. All streams in this study had some level of protection from agricultural practices in their basins. Although the intensity of agriculture is known to be a factor causing deterioration of invertebrate populations in past studies, the finding in this study indicated that the level of protection the stream received and other factors such as environmental setting and habitat could be more important to benthic invertebrates than the percentage of agriculture in the basin.

\section{REFERENCES CITED}

Bode, R.W., 1988, Quality assurance work plan for biological stream monitoring in New York State Stream Biomonitoring Unit, Bureau of Monitoring and Assessment, Division of Water, New York State Department of Environmental Conservation, Albany, N.Y.

Cuffney, T.F., Gurtz, M.E., and Meador, M.R., 1993a, Methods for collecting benthic invertebrate samples as part of the National Water-Quality Assessment Program: U.S. Geological Survey Open-File Report 93-406, $66 \mathrm{p}$.

1993b, Guidelines for the processing and quality assurance of benthic invertebrate samples collected as part of the National Water-Quality Assessment Program: U.S. Geological Survey Open-File Report 93-407, $80 \mathrm{p}$.

Fitzpatrick, F.A., Peterson, P.M., and Stewart, J.S., 1996, Habitat characteristics of benchmark streams in agricultural areas of eastern Wisconsin: U. S Geological Survey Water-Resources Investgations Report 964038-B, 35 p.

Helsel, D.R., 1987, Advantages of nonparametric procedures for analysis of water-quality data: Journal of Hydrological Sciences, v. 32, no. 2, p. 179-189.

Hilsenhoff, W.L., 1977, Use of arthropods to evaluate water quality of streams: Madison, Wis., Wisconsin Department of Natural Resources, Technical Bulletin 100, 15 p. 1982, Using a biotic index to evaluate water quality in streams: Madison, Wis., Wisconsin Department of Natural Resources, Technical Bulletin 132, 22 p. 1987, An improved biotic index of organic stream pollution: Great Lakes Entomologist, v. 20, p. 31-39. 1988, Rapid field assessment of organic pollution with a family-level biotic index: Journal of the North American Benthological Society, v. 7, p. 65-68.

Hotelling, H., 1933, Analysis of a complex of statistical variables into principal components: Journal of Educational Psychology, v. 24, p. 417-441, 498-520.

Hughes, R.M., Rexstad, W., and Bond, C.E., 1987, The relationship of aquatic ecoregions, river basins, and physiographic provinces to the ichthyogeographic regions of Oregon: Copeia, v. 2, p. 423-432.

Hunt, R.L., 1988, A compendium of 45 trout stream habitat development evaluations in Wisconsin during 1953 1985: Wisconsin Department of Natural Resources, Technical Bulletin 162, $80 \mathrm{p}$.

Iman, R.L, and Conover, W.J., 1983, A modern approach to statistics: New York, John Wiley and Sons, 497 p. 
Johnson, R.A., and Wichern, D.W., 1992, Applied multivariate statistical analysis (3rd ed.): Englewood Cliffs, N.J., Prentice-Hall, p. 356-395.

Leahy, P.P., Rosenshein, J.S., and Knopman, D.S., 1990, Implementation plan for the National Water-Quality Assessment Program: U.S. Geological Survey OpenFile Report 90-174, 10 p.

Lenat, D.R., 1988, Water quality assessment of streams using a qualitative collection method for benthic macroinvertebrates: Journal of the North American Benthological Society 7: p. 222-233.

Lillie, R.A., and Schlesser, R.A., 1994, Extracting additional information from biotic index samples: Great Lakes Entomologist, v. 27, no 3, p 129-136.

Lyons, J., 1989, Correspondence between the distribution of fish assemblages in Wisconsin streams and Omernik's ecoregions: American Midland Naturalist, v. 122, p. $163-182$.

Margalef, R., 1969, Diversity and stability in ecological systems: Biology, v. 22, p 25-37.

Meador, M.R., Cuffney, T.R., and Gurtz, M.E., 1993, Methods for collecting samples of fish communities as part of the National Water-Quality Assessment Program: U.S. Geological Survey Open-File Report 93-104, $40 \mathrm{p}$.

Merritt, R.W., and Cummins, K.W., eds., 1984, An introduction to the aquatic insects of North America ( $2 \mathrm{~d}$ ed.): Dubuque, Iowa, Kendall/Hunt Publishing, 722 p.

Neter, J., Wasserman, W., and Kutner, M.H., 1985, Applied linear statistical models (2nd ed.): Homewood, Ill., Irwin Publishers, $1,127 \mathrm{p}$.

Omernik, J.M., and Gallant, A.L., 1988, Ecoregions of the Upper Midwest States: Corvallis, Oreg., U.S. Environmental Protection Agency, Environmental Research Laboratory, EPA/600/3-88/037, 56 p.

Pajak, P. and others, 1994, Agricultural land use and reauthorization of the 1990 Farm Bill: Fisheries, v. 19, no. 12 , p. 22-27.

Pearson, K., 1901, On lines and planes of closest fit to systems of points in space: Philosophical Magazine, Sixth Series, v. 2, p. 559-572.

Plafkin, J.L., Barbour, M.T., Porter, K.D., Gross, S.K., and Hughes, R.M., 1989, Rapid bioassessment protocols for use in streams and rivers-Benthic macroinvertebrates and fish: Washington, D.C., U.S. Environmental Protection Agency, EPA/444/4-89/001, 117 p.

Porter, S.D., Cuffney, T.F., Gurtz, M.E., and Meador, M.R., 1993, Methods for collecting algal samples as part of the National Water-Quality Assessment Program: U.S. Geological Survey Open-File Report 93-409, 39 p.

Resh, V.H., and Grodhaus, G., 1983, Aquatic insects in urban environments, in Frankie, G.W., and Koehler, C.S., eds., Urban entomology-Interdisciplinary Perspectives: New York, Praeger Publications, p. 247276.
Rheaume, S.J., Stewart, J.S., Lenz, B.N., 1996, Environmental setting of benchmark streams in agricultural areas of Eastern Wisconsin: U. S Geological Survey Water-Resources Investigations Report 96-4038-A, $50 \mathrm{p}$.

Robertson, D.M., and Saad, D.A., 1996, Water-quality assessment of the Western Lake Michigan DrainagesAnalysis of available data on nutrients and suspended sediment, water years 1971-1990: U.S. Geological Survey Water-Resources Investigations Report 964012, $166 \mathrm{p}$.

Robins, C.R., Bailey, R.M., Bond, C.E., Brooker, J.R., Lachner, E.A., Lea, R.N., and Scott, W.B., 1991, Common and scientific names of fishes from the United States and Canada: Bethesada, Md., American Fisheries Society, Special Publication 20, 183 p.

Rosenberg, D.M., and Resh, V.H., eds., 1993, Freshwater biomonitoring and benthic macroinvertebrates: New York, Chapman and Hall, $488 \mathrm{p}$.

SAS Institute, Inc., 1990, SAS/STAT user's guide (4th ed.): Cary, N.C., SAS Institute, [variously paginated].

Tukey, J.W., 1977, Exploratory data analysis: Reading, Mass., Addison-Wesley, 668 p.

U.S. Bureau of the Census, 1991, 1990 census of population and housing, summary population and housing characteristics, Wisconsin: U.S. Department of Commerce, $1990 \mathrm{CPH}-1-51,370 \mathrm{p}$.

U.S. Environmental Protection Agency, 1991, Biological survey-fish survey of the Stockbridge-Munsee Reservation, Shawano County, Wisconsin, for estimating water resource quality: U.S. Environmental Protection Agency, Central Regional Laboratory, 100 p.

Washington, H. G., 1984 Diversity, biotic and similarity indices-A review with special relevance to aquatic ecosystems: Water Resources, v. 18, no. 6, p. 653-694.

Weber, C.I., ed., 1973, Biological field and laboratory methods for measuring the quality of surface waters and effluents: Cincinnati, Ohio, U.S. Environmental Protection Agency, EPA-670/4-73-001.

Whittier, T.R., Hughes, R.M., and Larsen, D.P., 1988, Correspondence between ecoregions and spatial patterns in stream ecosystems in Oregon: Canadian Journal of Fisheries and Aquatic Sciences, v. 45, p. 1264-1278.

Wisconsin Department of Natural Resources, 1980, Wisconsin trout streams: Wisconsin Department of Natural Resources Publication 6-3600 (80), 67 p.

- 1989, Wisconsin administrative code, chapter NR 102, water-quality standards for Wisconsin surface waters: Madison, Register, February 1989, no. 398, 14 p. 1990, A non-point source control plan for the east and west branches of the Milwaukee River-Priority Watershed Project: Wisconsin Department of Natural Resources Milwaukee River Priority Watersheds Program, $46 \mathrm{p}$. 

APPENDIX A 


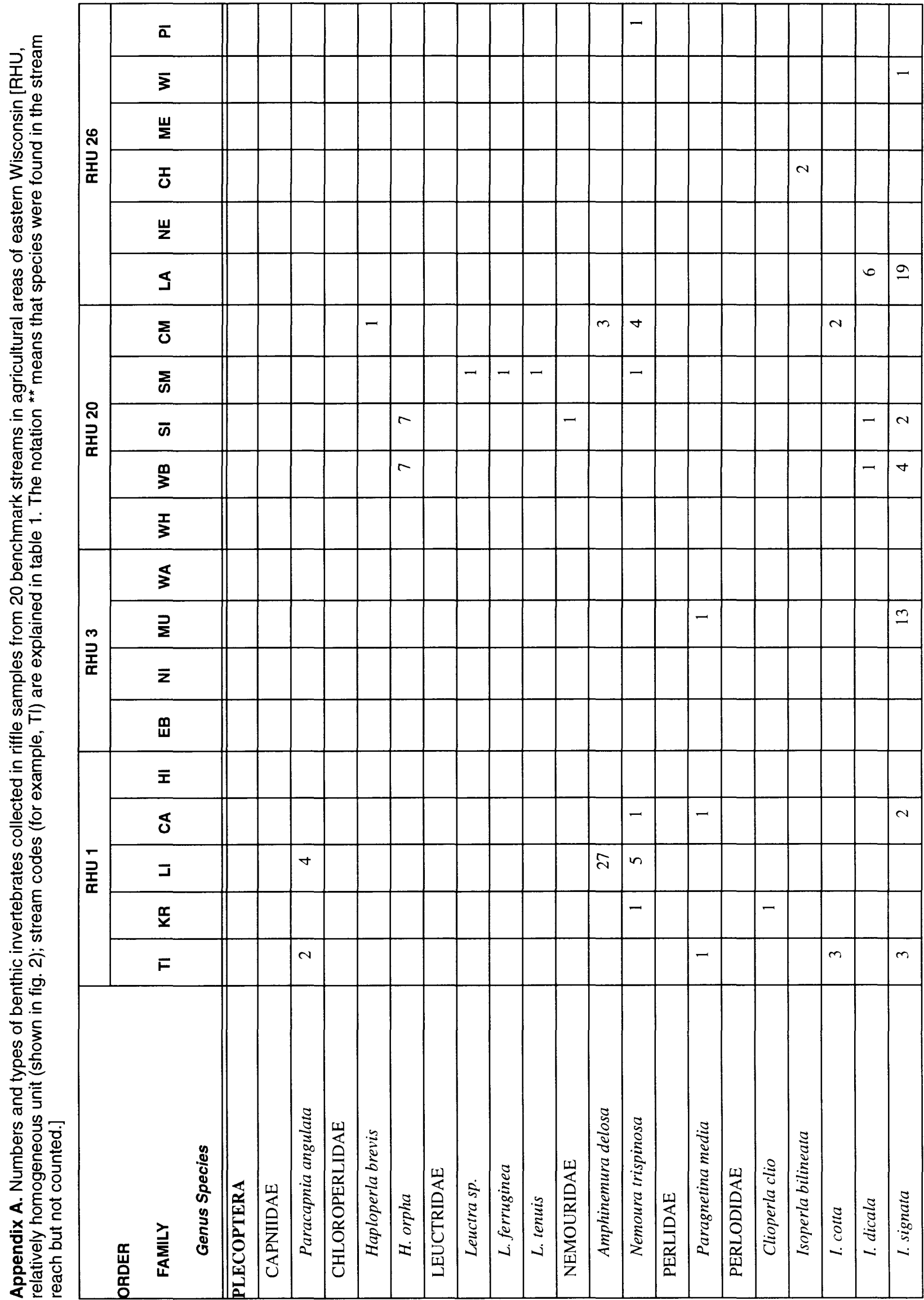




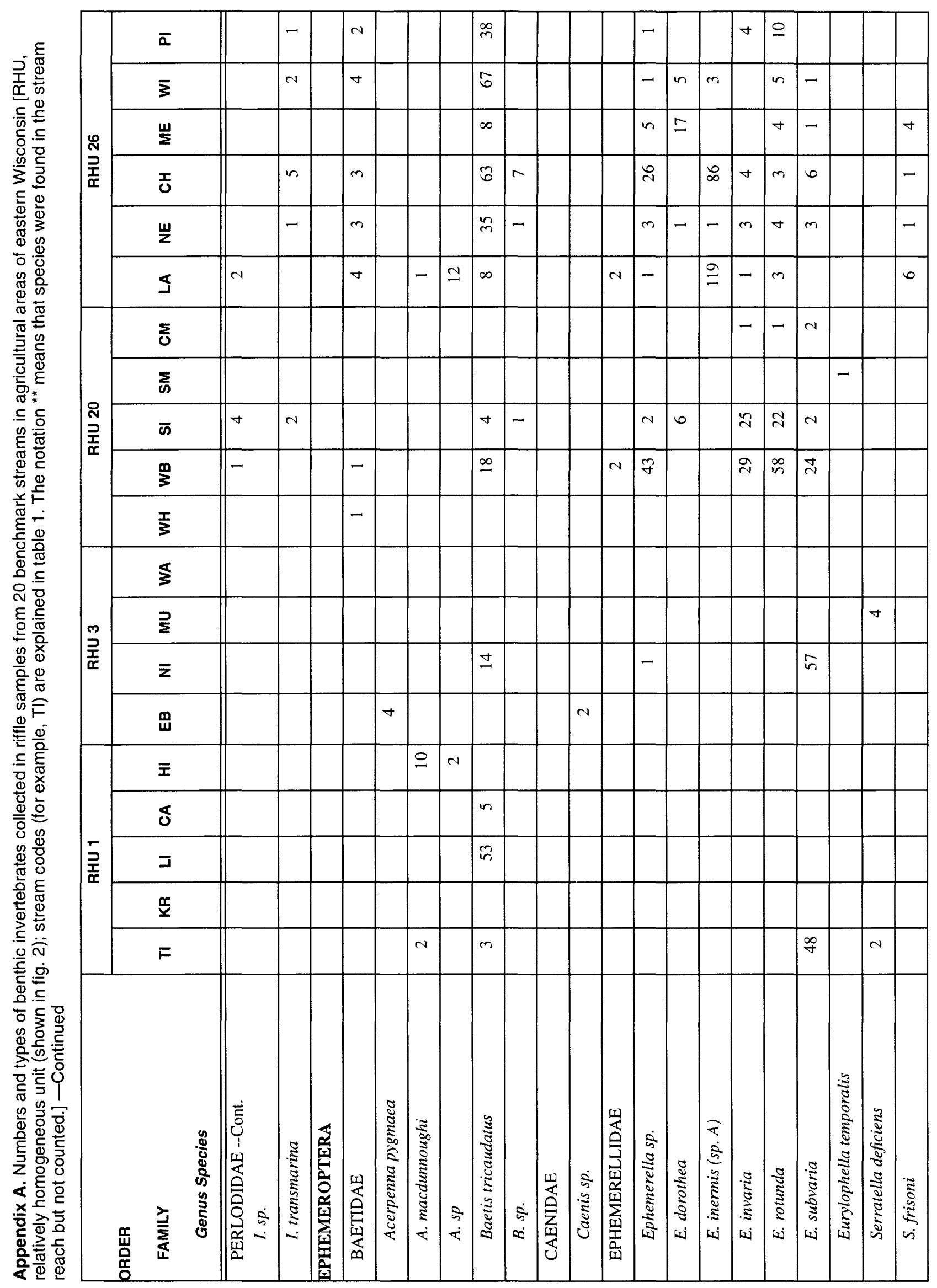




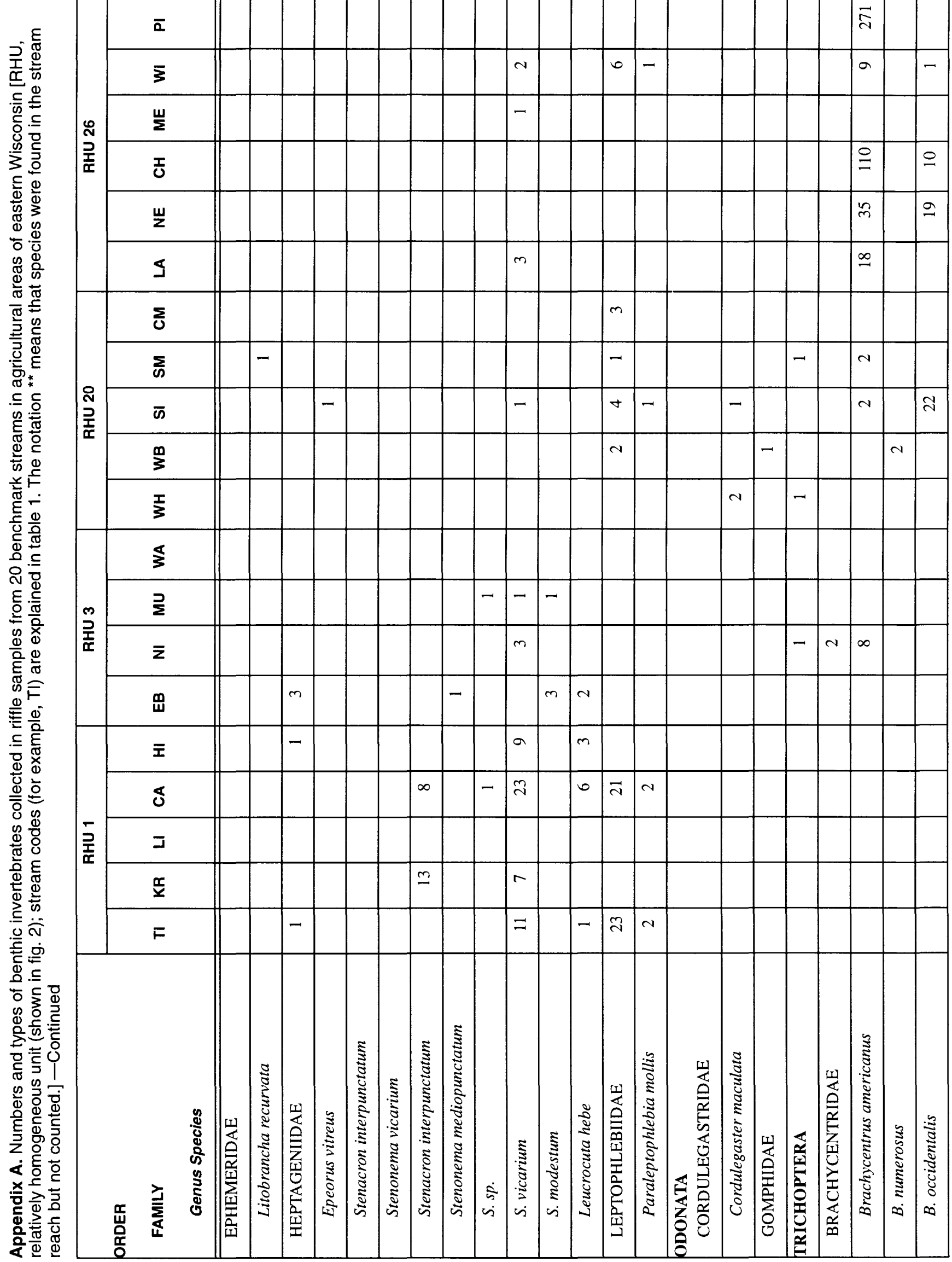




\begin{tabular}{|c|c|c|c|c|c|c|c|c|c|c|c|c|c|c|c|c|c|c|c|c|c|c|c|c|c|}
\hline \multirow{6}{*}{\multicolumn{2}{|c|}{ 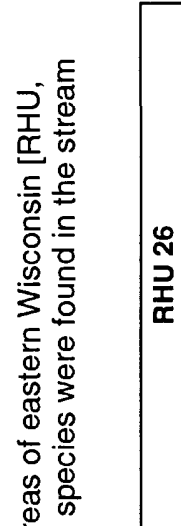 }} & $\bar{a}$ & & 10 & & & & & & & $a$ & - & & & & & & & & & & & & & $\vec{\sim}$ \\
\hline & & $\xi$ & & & & & & & & & & & 12 & & & & & & & 요 & & & - & & $=$ \\
\hline & & 岂 & & & - & & & & & & & & $N$ & & & & & & $N$ & 0 & $n$ & & & - & $n$ \\
\hline & & J & & & & & & & & & & & & & & & & & $N$ & $\ddot{\sim}$ & & & & & $\simeq$ \\
\hline & & ш & & & - & $n$ & $\stackrel{\dot{n}}{n}$ & & & & & & - & N & & & & & $m$ & & - & & $N$ & & $\cong$ \\
\hline & & 5 & & in & & & & & & & & - & & & & & & & & $\infty$ & & & & & in \\
\hline $\begin{array}{l}\bar{\sigma} \\
\stackrel{\widetilde{\sigma}}{丂}\end{array}$ & \multirow{5}{*}{$\begin{array}{l}\stackrel{R}{N} \\
\frac{T}{\pi} \\
\mathbb{x}\end{array}$} & $\sum_{0}$ & & & & & & & & & in & $\sim$ & $m$ & & & & & & & in & & & & & $=$ \\
\hline . & & $\sum_{\infty}$ & & & & & & & $=$ & & & & & & & & & & & & & & & & \\
\hline 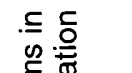 & & $\bar{\omega}$ & & - & & & & & & & & & $n$ & & & & & & & $\nabla$ & & & - & & - \\
\hline 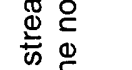 & & $\stackrel{m}{\xi}$ & & & & $N$ & & & & & & & $N$ & & & & & & & $r$ & & & & & 0 \\
\hline$\sum_{\underline{0}}^{\mathbb{E}}$ & & $\frac{T}{\xi}$ & & & & & & & & & & & & & & & & & & & & & & & \\
\hline $\begin{array}{l}\frac{\pi}{ \pm} \\
0 . \subseteq \\
0.5\end{array}$ & \multirow{4}{*}{ 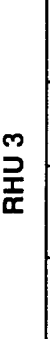 } & $\$$ & & & & & & & & & & & & & & & & & & N & & & $\sim$ & & \\
\hline ¿ & & $\stackrel{P}{\Sigma}$ & & & & & & & & & & & & & & & & $\stackrel{m}{m}$ & - & $\stackrel{\sim}{\sim}$ & $\underline{0}$ & $m$ & $\sim$ & & ஜீ \\
\hline 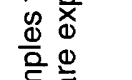 & & $\overline{\mathbf{z}}$ & & a & & & & & & & 8 & $\infty$ & & & & & & & $\nabla$ & $m$ & & & $m$ & & ㄱ \\
\hline 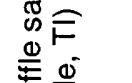 & & 畠 & & & & & & & & & & & $N$ & & & & & $=$ & - & $\infty$ & ন & $=$ & & & \\
\hline 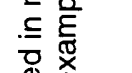 & \multirow{5}{*}{$\underset{\substack{\mathbf{x} \\
\boldsymbol{\alpha}}}{ }$} & $\overline{\mathbf{x}}$ & & & & & & & & & $\infty$ & & & & & $N$ & & $n$ & $\nabla$ & 웅 & $N$ & & & & 苂 \\
\hline 芯 & & $\delta$ & & - & & & & & & & $n$ & & & & & & & & - & প্ & & & & $\sim$ & \\
\hline 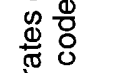 & & J & & $\mathrm{d}$ & & & & & & & t & - & & & & & & & & & & & & & $\sim$ \\
\hline 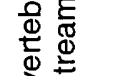 & & $\frac{\mathfrak{c}}{\boldsymbol{x}}$ & & & & & & & & & & & & & & & & & & $\stackrel{\mathscr{F}}{\sim}$ & & & & & 0 \\
\hline 을 & & $F$ & & & & & & & & & $r$ & & & & & - & & & - & $\bar{m}$ & & & $\mathrm{~N}$ & $m$ & $\bar{\sim}$ \\
\hline 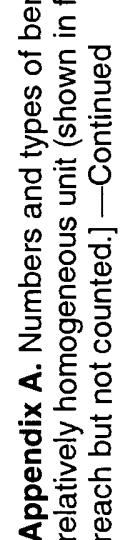 & & 戦 & 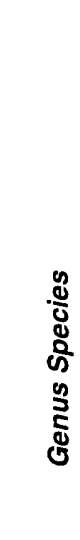 & 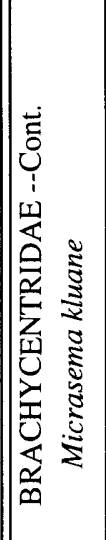 & 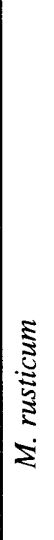 & $\begin{array}{l}\dot{5} \\
\dot{5}\end{array}$ & 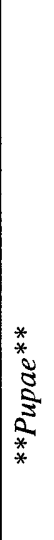 & 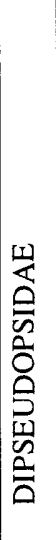 & 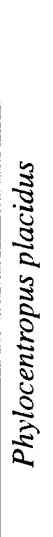 & 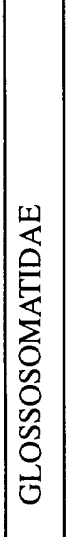 & 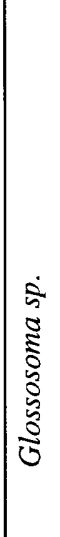 & 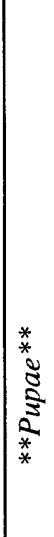 & 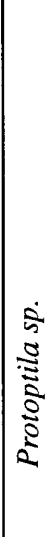 & 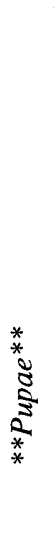 & 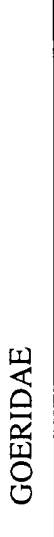 & 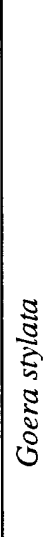 & 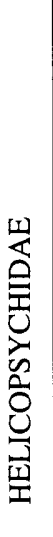 & 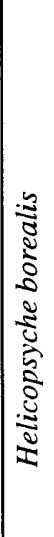 & 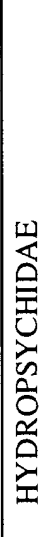 & 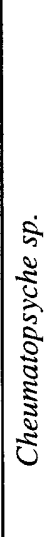 & 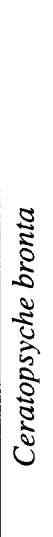 & $\mid \begin{array}{c}0 \\
0 \\
0 \\
0 \\
0 \\
0 \\
0 \\
0 \\
0 \\
0 \\
0 \\
0\end{array}$ & 仓े & 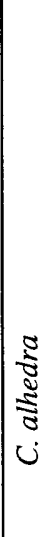 & 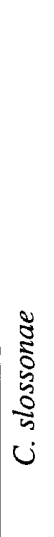 \\
\hline
\end{tabular}




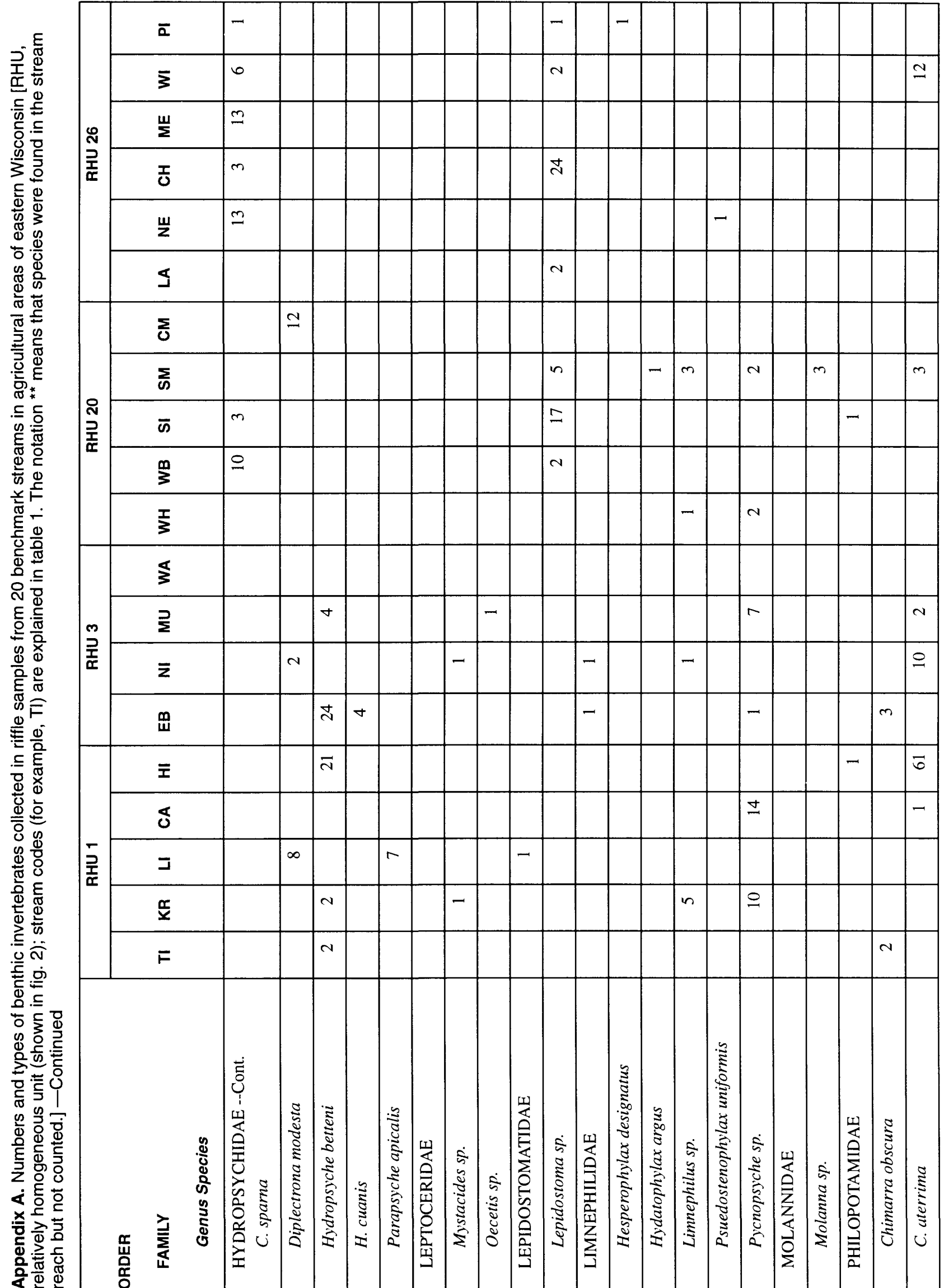




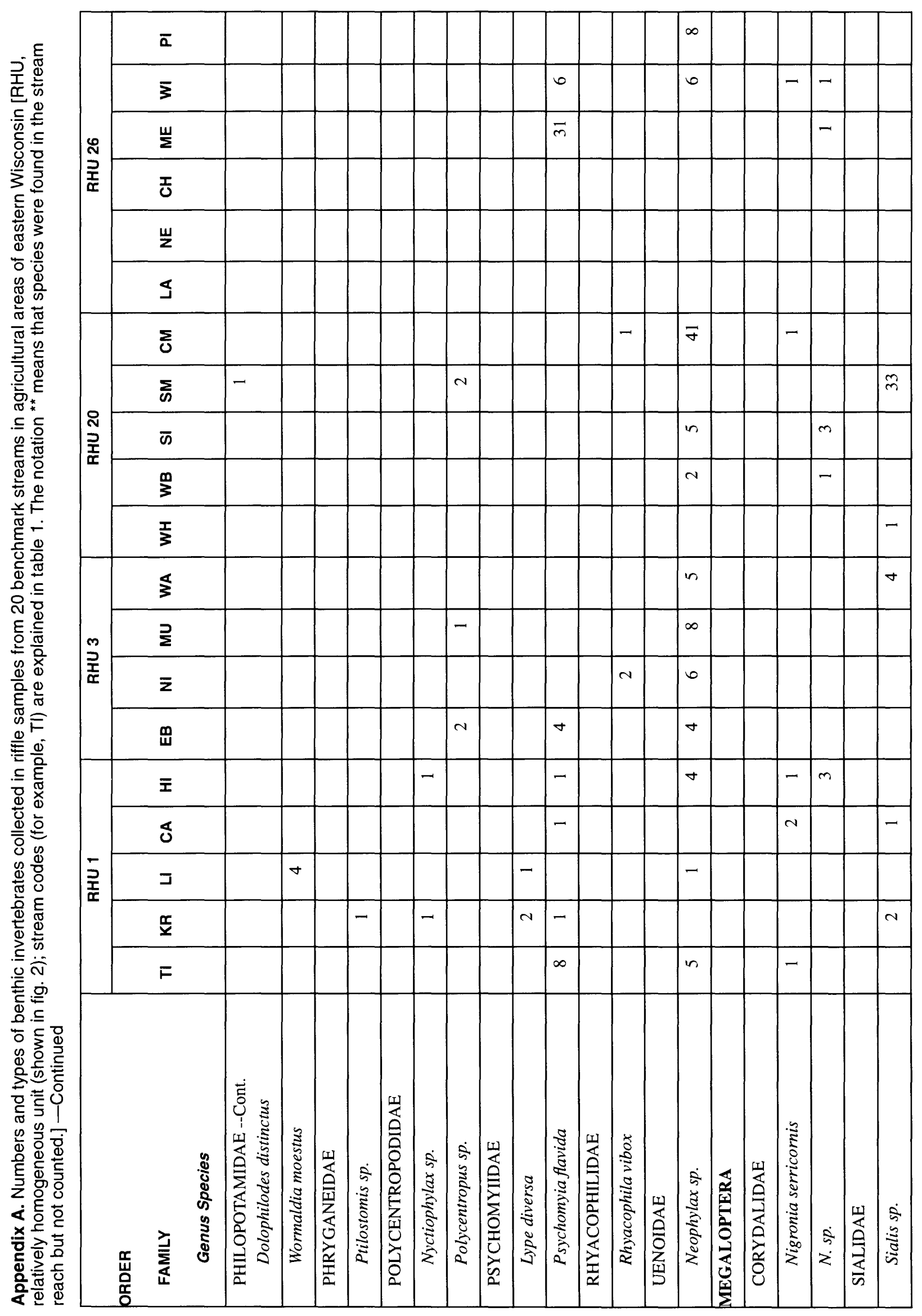




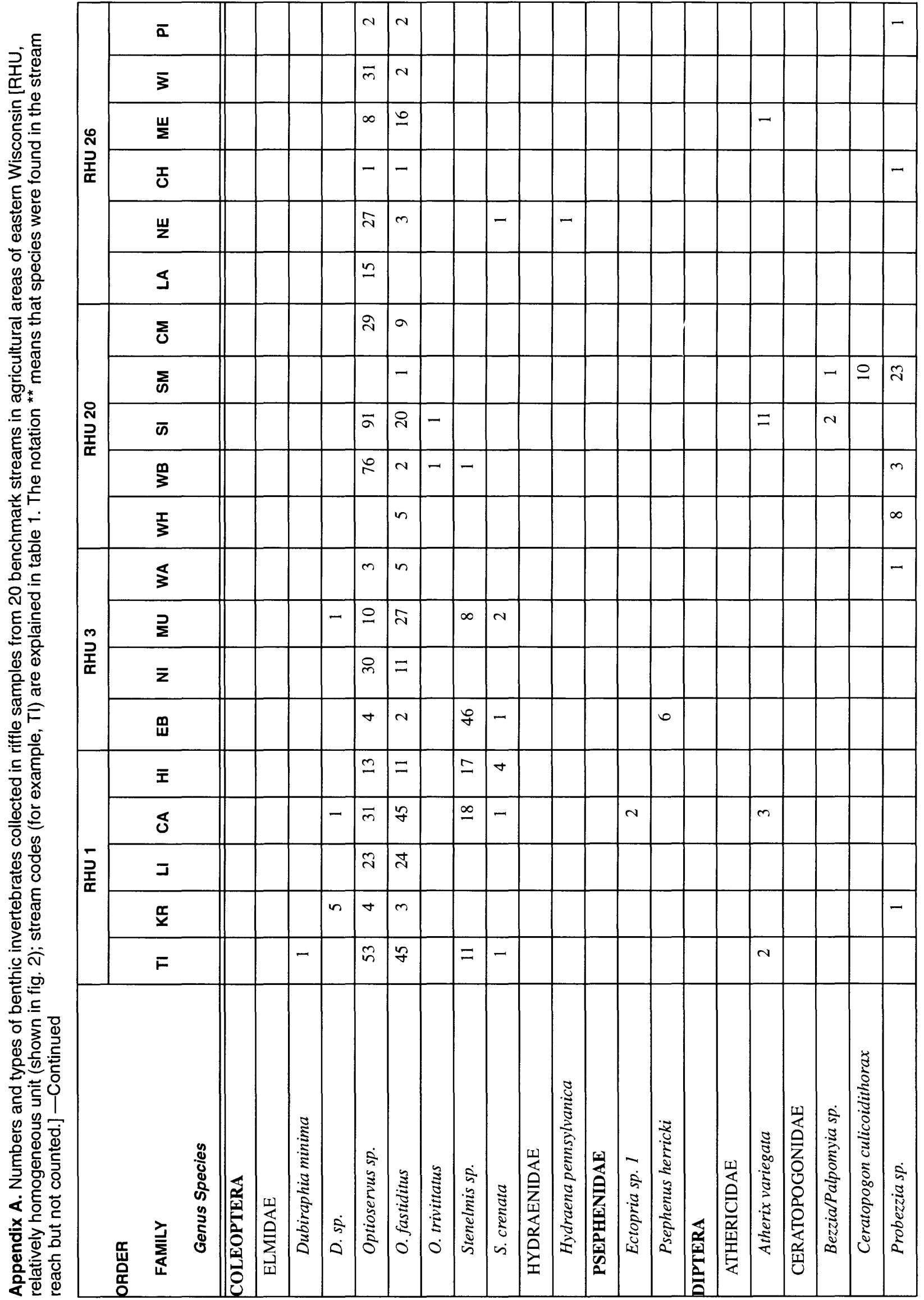




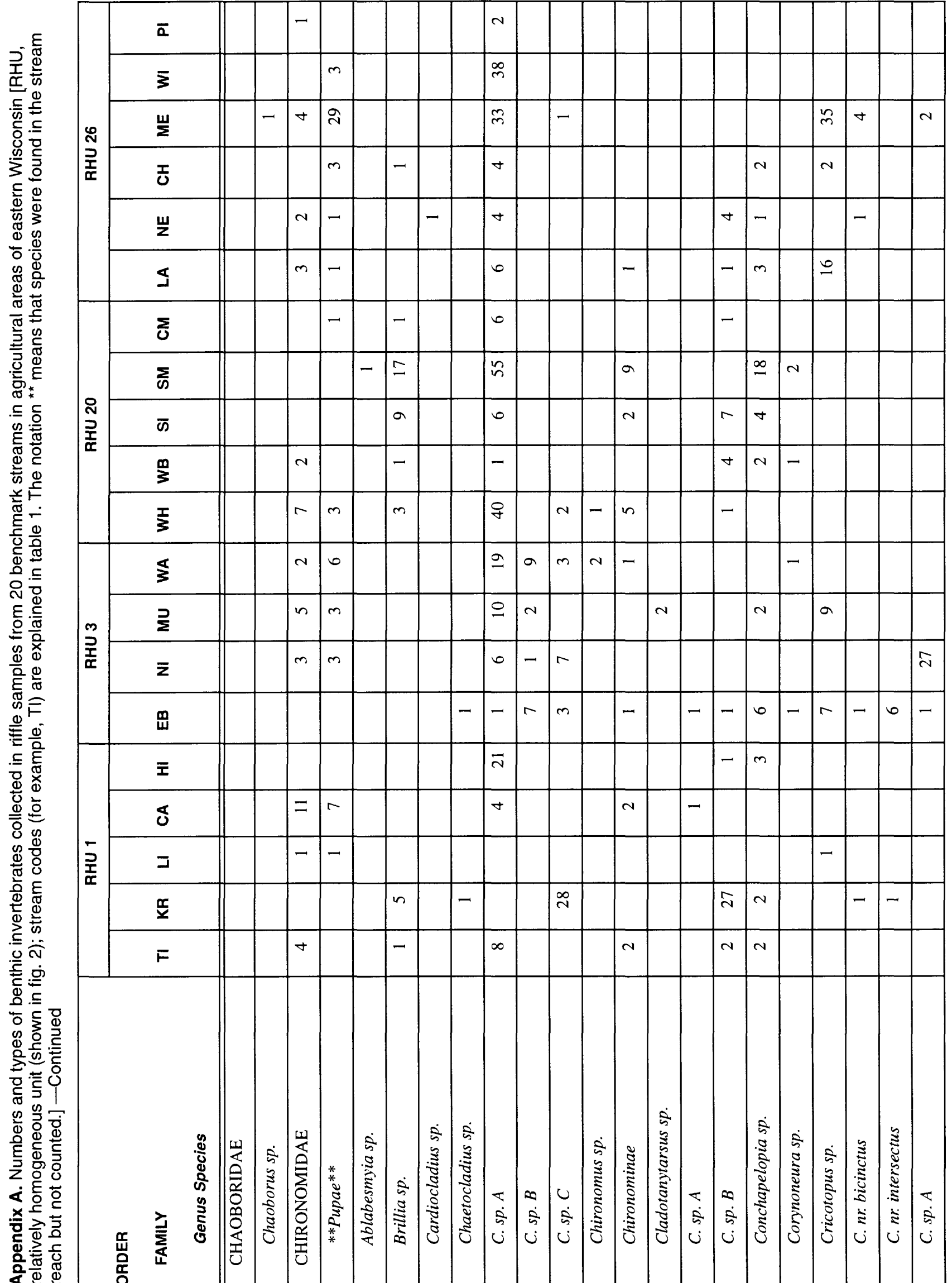




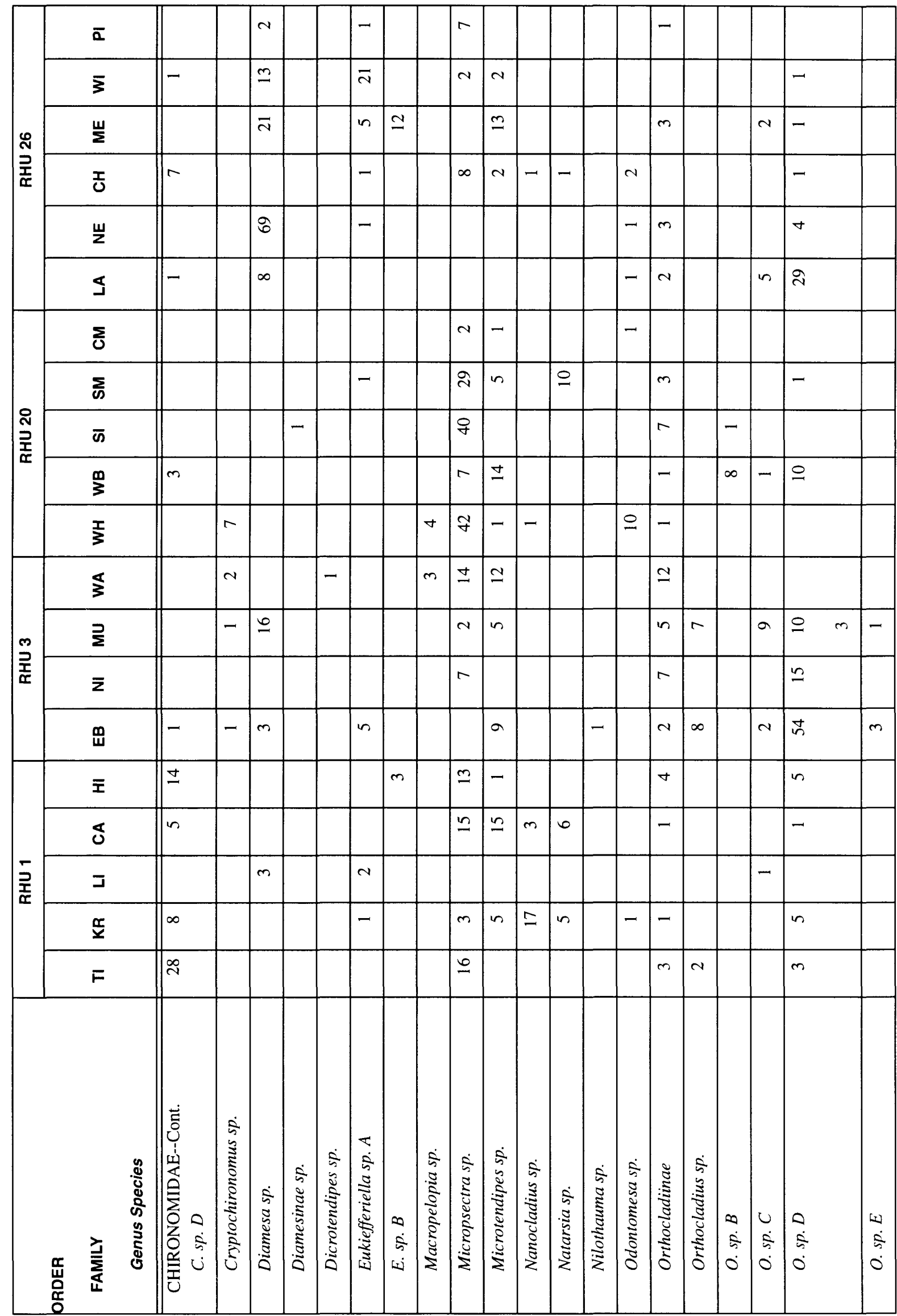




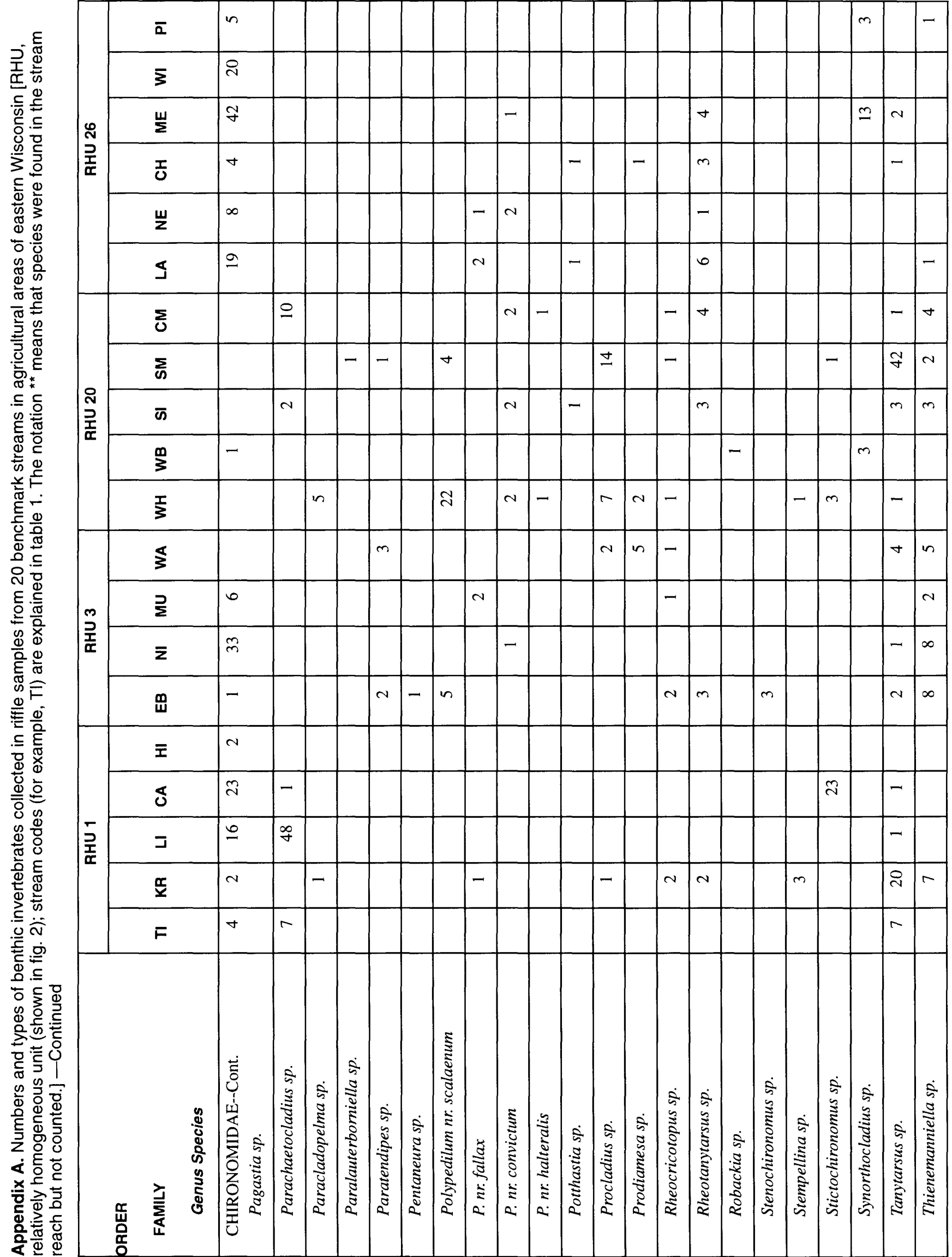




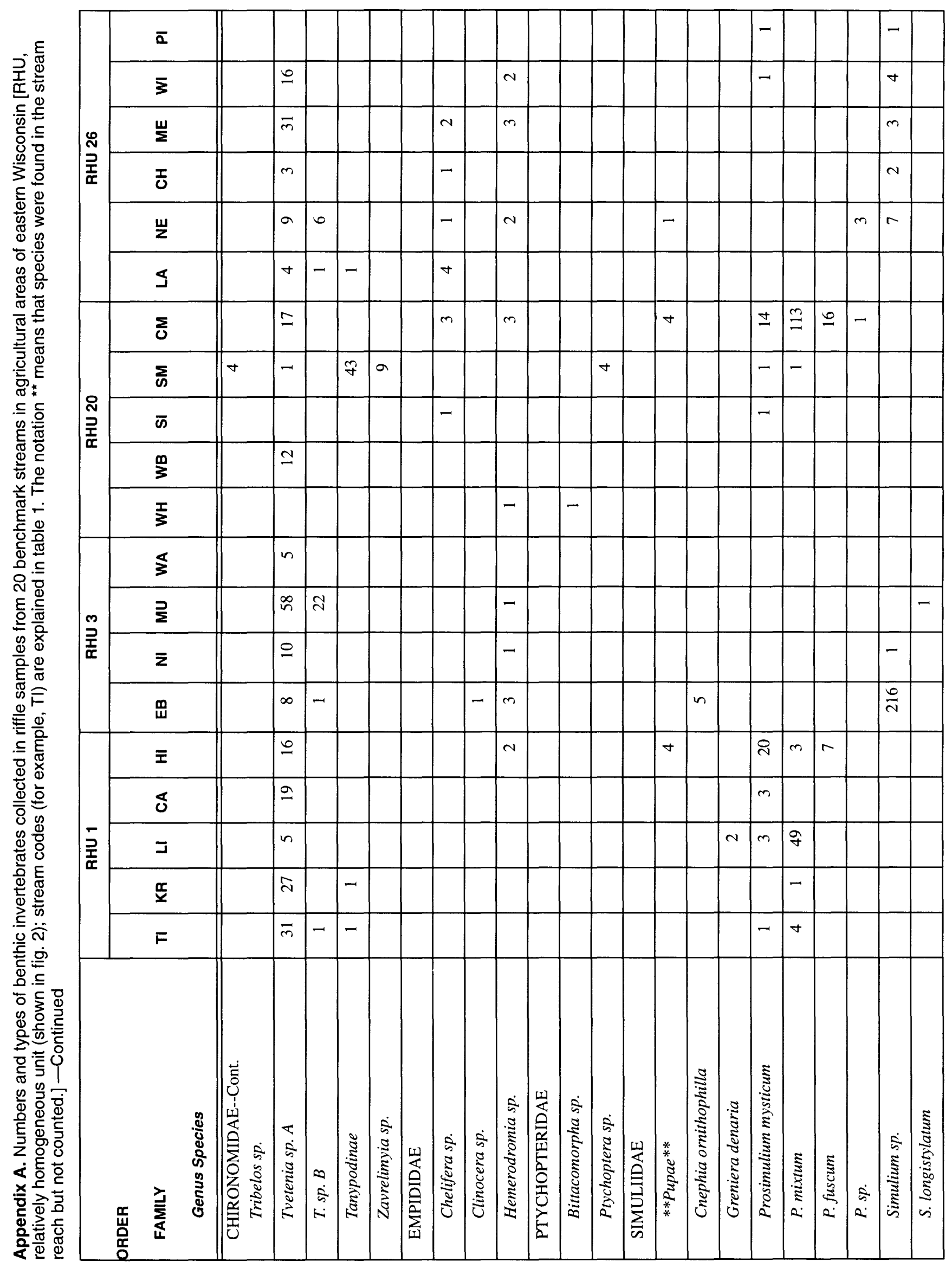




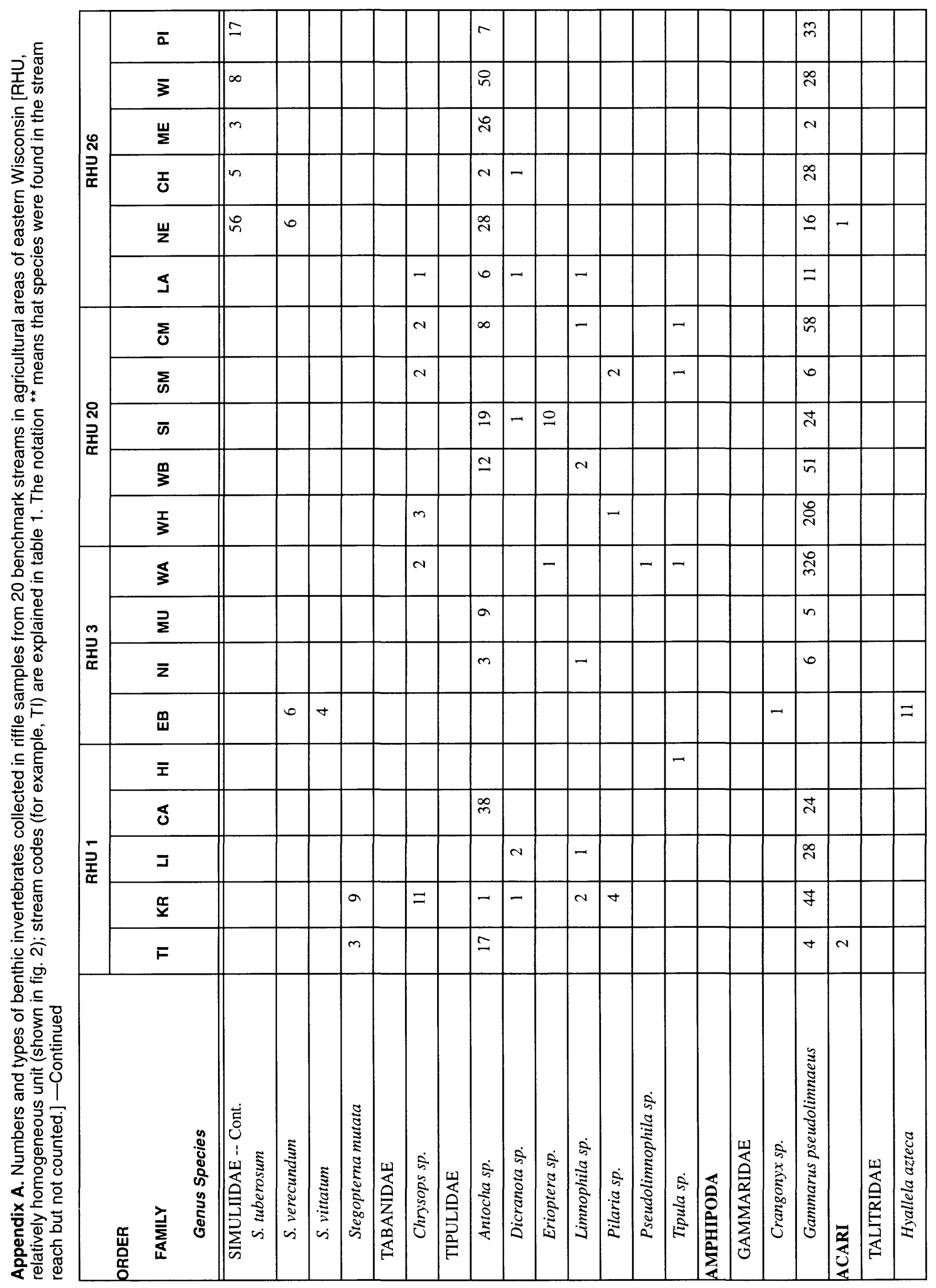




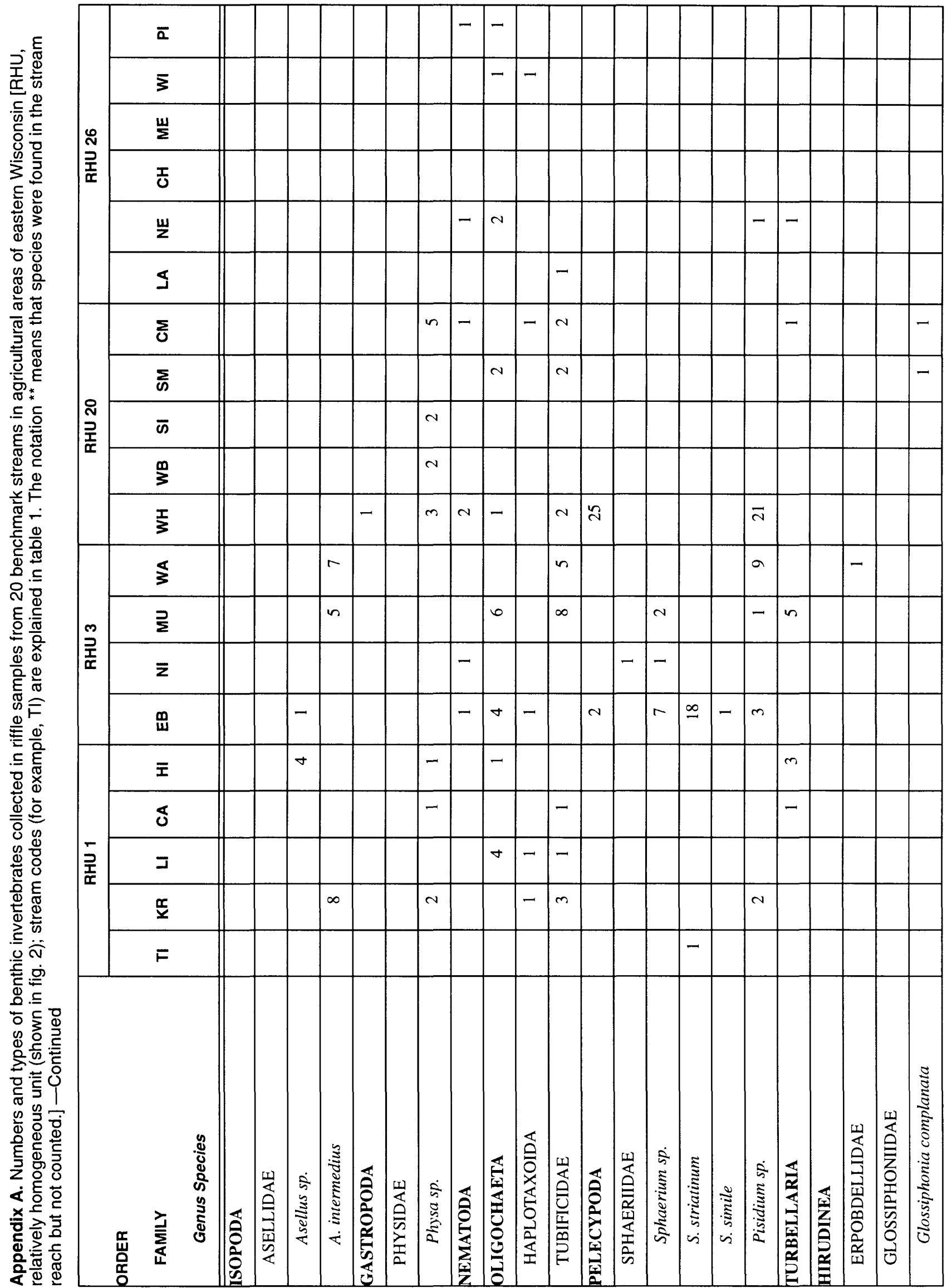




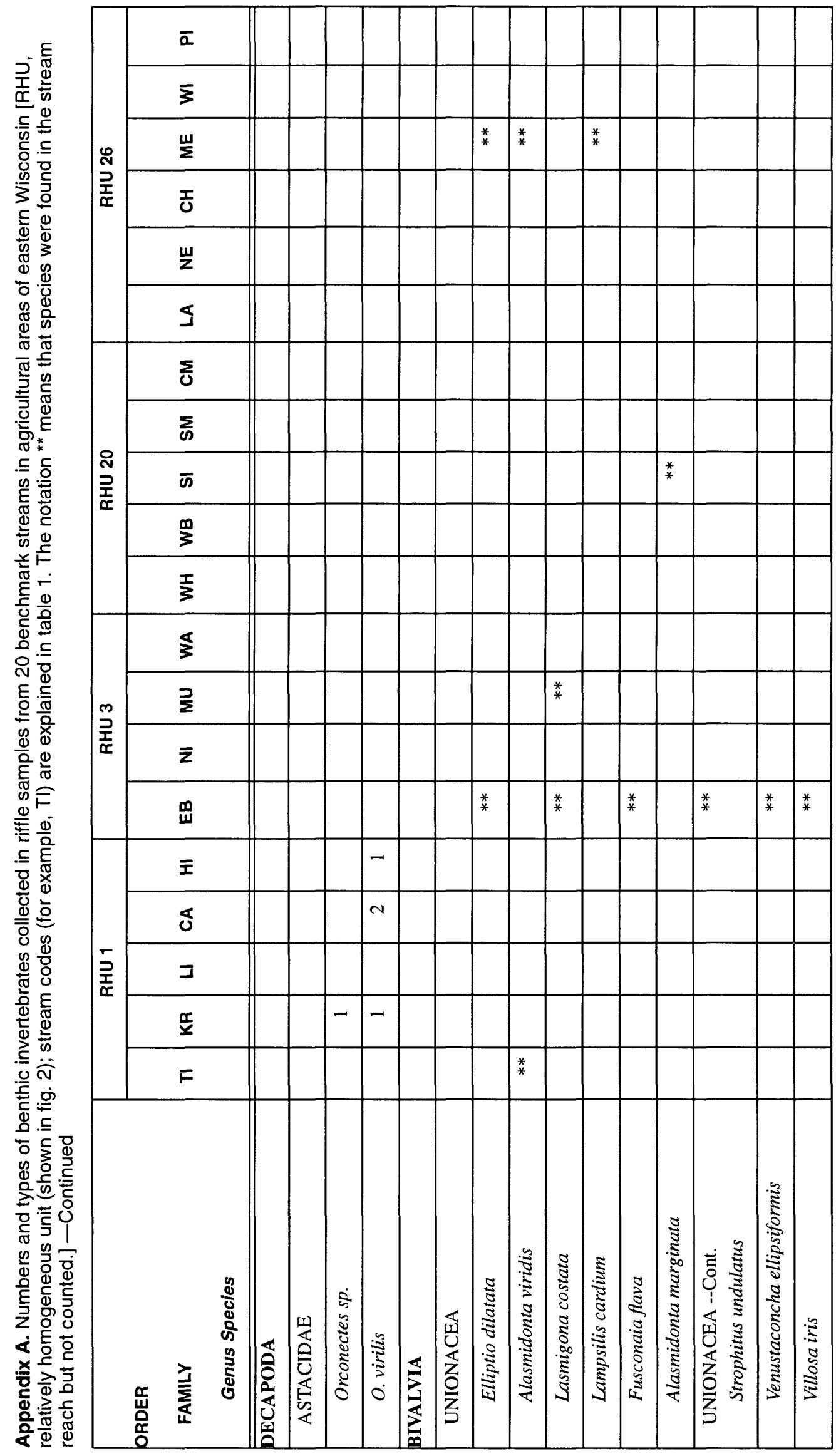




\section{ERRATA SHEET -- Water Resources Investigation Report 96- 4038-C, Benthic Invertebrates of Benchmark Streams in Agricul- tural Areas of Eastern Wisconsin-Western Lake Michigan Drain- ages.}

PLEASE NOTE THE FOLLOWING ERROR:

TABLE 1, PAGE 5:

- Several incorrect values of stream order were reported and the values in the columns "Latitude" and "Longitude" were transposed. A corrected TABLE 1 has been included in it's entirety.

IN TEXT TABLES, PAGE 7:

-The range for the HBI water-quality classification 'very good' should be 3.51-4.25 -- the range $3.51-4.50$ is incorrect.

- The range for the FBI water-quality classification 'very good' should be 3.51-4.50 -- the range $3.51-4.25$ is incorrect.

FIGURE 5A, PAGE 20:

- The group $\mathrm{X}$ boxplot is incorrect. Figure 5A should appear as:

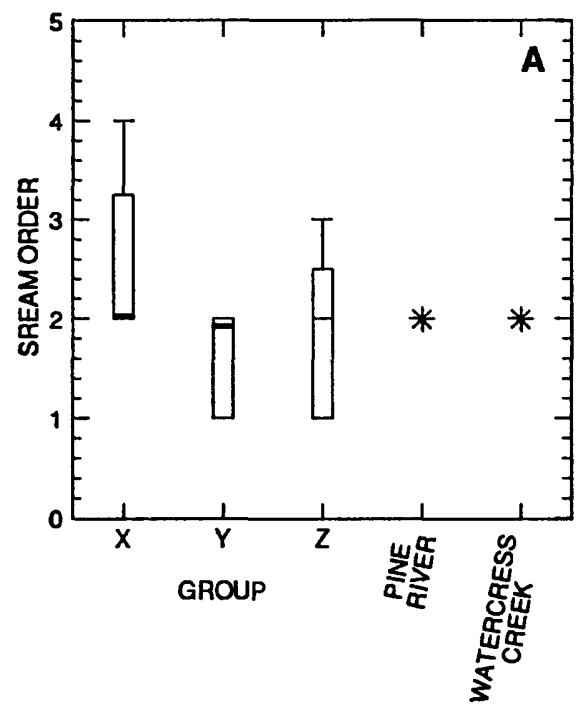

EXPLANATION

Outlier data value iess than or equal to 3

and more than 1.5 times the

interquartile range outside the quaritie

Data value less than or equal to 1.5 times the

interquartile range outside the quartile

75ith percentile

Median

25th percentile 